\title{
Placental Protein 13 (PP13) - a placental immunoregulatory galectin protecting pregnancy
}

\section{Nándor GáborThan ${ }^{1,2,3,4}$ * , Andrea Balogh ${ }^{5}$, Roberto Romero ${ }^{1}$, Éva Kárpáti ${ }^{5}$, Offer Erez ${ }^{6}$, András Szilágyi ${ }^{4}$, Ilona Kovalszky ${ }^{7}$, Marei Sammar ${ }^{8}$, Sveinbjorn Gizurarson ${ }^{9}$, János Matkó $^{5}$, Péter Závodszky ${ }^{4}$, Zoltán Papp ${ }^{3}$ and Hamutal Meiri ${ }^{10,11}$ *}

\author{
${ }^{1}$ Perinatology Research Branch, Eunice Kennedy Shriver National Institute of Child Health and Human Development, National Institutes of Health, U.S. Department \\ of Health and Human Services, Bethesda, MD, and Detroit, MI, USA \\ ${ }^{2}$ Department of Obstetrics and Gynecology, Wayne State University School of Medicine, Detroit, MI, USA \\ ${ }^{3}$ Maternity Private Department, Kútvölgyi Clinical Block, Semmelweis University, Budapest, Hungary \\ ${ }^{4}$ Institute of Enzymology, Research Centre for Natural Sciences, Hungarian Academy of Sciences, Budapest, Hungary \\ ${ }^{5}$ Department of Immunology, Eötvös Loránd University, Budapest, Hungary \\ ${ }^{6}$ Department of Obstetrics and Gynecology, Soroka University Medical Center, Ben-Gurion University of the Negev, Beer-Sheva, Israel \\ 7 First Department of Pathology and Experimental Cancer Research, Semme/weis University, Budapest, Hungary \\ ${ }^{8}$ Prof. Ephraim Katzir Department of Biotechnology Engineering, ORT Braude College, Karmiel, Israel \\ ${ }^{9}$ Faculty of Pharmaceutical Sciences, School of Health Science, University of Iceland, Reykjavik, Iceland \\ ${ }^{10}$ TeleMarpe Ltd., Tel Aviv, Israel \\ "Hylabs Ltd., Rehovot, Israel
}

\section{Edited by:}

Sinuhe Hahn, University Clinics Basel, Switzerland

\section{Reviewed by:}

Stefan Gebhardt, Stellenbosch

University, South Africa

Kai Fang, University of California Los

Angeles, USA

\section{*Correspondence:}

Nándor Gábor Than, Institute of Enzymology, Research Centre for Natural Sciences, Hungarian Academy of Sciences, Magyar tudósok körútja

2, Budapest $\mathrm{H}-1117$, Hungary e-mail: than.gabor@ttk.mta.hu; Hamutal Meiri, TeleMarpe Ltd., 12 Barasani Street, Tel Aviv 69127, Israel e-mail: hamutal62@hotmail.com
Galectins are glycan-binding proteins that regulate innate and adaptive immune responses, and some confer maternal-fetal immune tolerance in eutherian mammals. A chromosome 19 cluster of galectins has emerged in anthropoid primates, species with deep placentation and long gestation. Three of the five human cluster galectins are solely expressed in the placenta, where they may confer additional immunoregulatory functions to enable deep placentation. One of these is galectin-13, also known as Placental Protein 13 (PP13). It has a "jelly-roll" fold, carbohydrate-recognition domain and sugar-binding preference resembling other mammalian galectins. PP13 is predominantly expressed by the syncytiotrophoblast and released from the placenta into the maternal circulation. Its ability to induce apoptosis of activated T cells in vitro, and to divert and kill T cells as well as macrophages in the maternal decidua in situ, suggests important immune functions. Indeed, mutations in the promoter and an exon of LGALS13 presumably leading to altered or non-functional protein expression are associated with a higher frequency of preeclampsia and other obstetrical syndromes, which involve immune dysregulation. Moreover, decreased placental expression of PP13 and its low concentrations in first trimester maternal sera are associated with elevated risk of preeclampsia. Indeed, PP13 turned to be a good early biomarker to assess maternal risk for the subsequent development of pregnancy complications caused by impaired placentation. Due to the ischemic placental stress in preterm preeclampsia, there is increased trophoblastic shedding of PP13 immunopositive microvesicles starting in the second trimester, which leads to high maternal blood PP13 concentrations. Our meta-analysis suggests that this phenomenon may enable the potential use of PP13 in directing patient management near to or at the time of delivery. Recent findings on the beneficial effects of PP13 on decreasing blood pressure due to vasodilatation in pregnant animals suggest its therapeutic potential in preeclampsia.

Keywords: actin cytoskeleton, biomarker, danger signal, evolution, extracellular vesicles, glycans, lectins, maternal-fetal interface

\section{PREFACE}

Many authors of this review have collaborated with Dr. Hans Bohn, the discoverer of Placental Protein 13 (PP13), who passed away on January 25,2014 . We dedicate this manuscript to his memory. His scientific legacy and enormous contribution to placental protein research have strongly influenced placentology and inspired our studies on PP13 (1).

Hans Bohn was born in Munich on October 18, 1928. He graduated in 1954 and completed his doctoral thesis in 1956 in chemistry at the University of Würzburg. A research fellowship starting in 1963 in the Protein Research Laboratory at the University of Pittsburgh was critical in directing his interest in protein research. After two years, Dr. Bohn returned to Germany to work on proteins in Behringwerke in Marburg/Lahn (Figure 1A). He was the first to isolate factor XIII from human placenta for the treatment of patients with factor XIII deficiency and wounds after injury or surgery, and a side-fraction of this experiment yielded human placental lactogen. This experience strongly influenced him to 
focus his research on the systematic isolation and characterization of placental, endometrial and pregnancy serum proteins. These studies have greatly supported our knowledge on pregnancyrelated proteins and their application in the diagnosis of pregnancy complications (1).

Dr. Hans Bohn processed large amounts of human placental, amniotic fluid and serum specimens and utilized combinations of classical fractionation techniques to isolate more than 50 proteins, which he named sequentially. He characterized these proteins for their physico-chemical characteristics, and then developed specific rabbit antisera against them for further protein purification and for the development of immunoassays to determine these proteins' diagnostic significance. In collaboration with scientists around the world, Dr. Bohn also determined the amino acid sequence as well as biological functions of many of these. Among the proteins he isolated were Placental Protein (PP) 4 (annexin-V), PP5 (tissue factor pathway inhibitor-2, TFPI-2), PP10 (plasminogen activator inhibitor-2, PAI-2), PP12 (insulin-like growth factor binding protein-1, IGFBP-1) and PP13 (galectin-13), which were subsequently identified to be important regulators of the fundamental processes in pregnancy (1).

Dr. Bohn's collaboration with Professor Gábor N. Than (University of Pécs, Pécs, Hungary) had a fundamental impact on the cloning, sequencing, structural, and molecular biological characterization of a large number of PPs including PP13, and their pioneering collaborative research significantly improved our understanding on the biological role and diagnostic significance of these proteins in pregnancy complications and malignancies. Beyond these scientific discoveries, their friendship and close collaboration strongly inspired a new generation of scientists. The existing knowledge and advancements in the field were summarized in their book entitled Advances in Pregnancy-Related Protein Research, co-written with Dr. Dénes G. Szabó in 1993 (2) (Figure 1B).

For Dr. Bohn's founding research and discovery of PP14 (glycodelin), he shared the prestigious Abbott Award in 1997. His remarkable contributions to placental and pregnancy-related protein research were published in 198 research articles. Dr. Bohn continued to contribute to placental protein research after his retirement, and closely followed the studies implementing novel molecular and cellular biological techniques on the proteins he isolated, leading to further discoveries and improvements in clinical diagnostics and patient care (1).

Dr. Hans Bohn was an exceptional scientist, an enthusiastic catalyzer of collaborations and friendships who inspired many peers and followers. He was a wonderful, kind and charismatic person, a silent giant, who will be greatly missed.

\section{THE DISCOVERY AND MOLECULAR CHARACTERIZATION OF PP13}

\section{ISOLATION, PURIFICATION AND PHYSICO-CHEMICAL CHARACTERIZATION OF PP13}

Dr. Bohn's scientific vision combined with his thorough work using state-of-the-art methods of the 70's and 80 's yielded the discovery of 26 soluble placental tissue proteins, among which PP13 was purified, physico-chemically characterized and described in 1983 (3). Dr. Bohn homogenized term placental tissues and
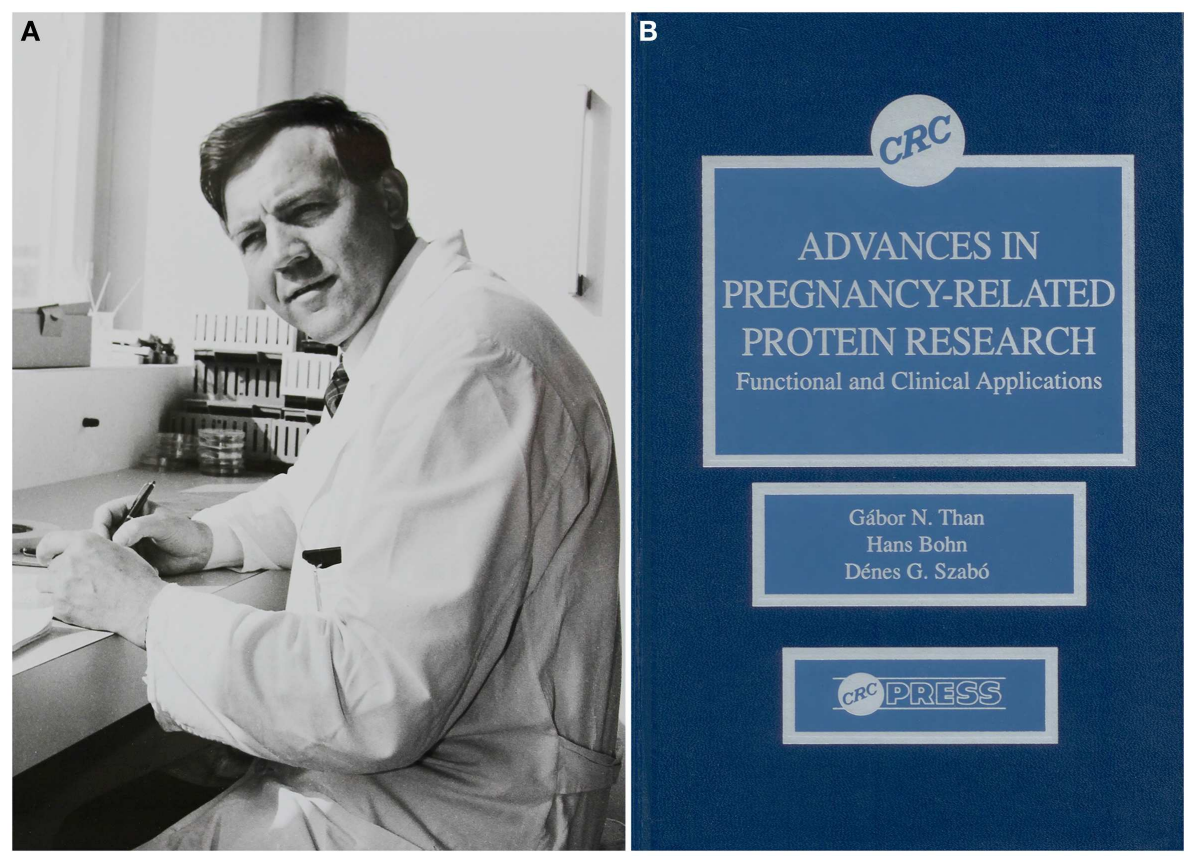

FIGURE 1 | Dr. Hans Bohn and his scientific legacy in pregnancy-related protein research. (A) Dr. Hans Bohn is depicted in his Protein Laboratory at Behringwerke (Marburg/Lahn, Germany), where he discovered and isolated more than 50 placental, endometrial and pregnancy serum proteins including Placental Protein 13 (PP13), and developed specific antisera and immunosassays for them between 1965 and 1989. The photo was obtained as a courtesy from Gabriele Bohn. (B) A book co-written by Hans Bohn, Gábor N. Than and Dénes G. Szabó published in the USA summarized the existing knowledge in the research field in 1993 
fractionated the protein extracts by a step-wise process that included Rivanol and ammonium sulphate fractionation, gelfiltration, ethanol precipitation, and immunoabsorption techniques. The resulting PP13 protein was $>99 \%$ pure, and SDSpolyacrylamide gel electrophoresis found it to be composed of two identical $\sim 16 \mathrm{kDa}$ subunits held together by disulphide bonds. The carbohydrate content of PP13 was found negligible, a feature that later became important in understanding its functions (2, 3). Utilizing the purified PP13-specific rabbit antiserum, an electroimmunoassay and an Ouchterlony's gel-diffusion test found an average amount of $3.7 \mathrm{mg}$ PP13 in human term placentas and detected PP13 solely in the placenta among fetal and adult tissues. The sensitivity of a radioimmunoassay $(0.8 \mathrm{ng} / \mathrm{ml})$ that utilized this rabbit antiserum was insufficient to detect PP13 in maternal and fetal serum or in amniotic fluid (2-4). Indeed, this is in accord with the $0.1-0.4 \mathrm{ng} / \mathrm{ml}$ concentration range of PP13 in maternal blood as was discovered with sandwich ELISA techniques using mouse monoclonal antibodies a decade later (5).

\section{CLONING, SEQUENCING AND INITIAL MOLECULAR BIOLOGICAL ANALYSIS OF PP13}

Professor Gábor N. Than's team in Hungary isolated the fulllength cDNA (GenBank Acc. No.: AF117383) encoding PP13 from a human placental cDNA expression library using Dr. Bohn's rabbit anti-PP13 antiserum. Sequence analysis revealed a 578 bp insert with a 417 bp open reading frame encoding a 139 amino-acid protein (6). The predicted molecular mass and amino-acid composition of the cloned protein corresponded with Dr. Bohn's estimate of the purified PP13 protein. A BLAST search of nucleotide and protein sequences showed PP13 to be homologous to members of the beta-galactoside binding galectin family, and computer analysis detected 8 out of 16 invariant residues in galectins conserved in PP13, suggesting its place in the galectin family (6). The highest sequence similarity of PP13 was found with the eosinophil Charcot-Leyden Crystal (CLC) protein, which forms crystals at sites of eosinophil-associated inflammation (7), a phenomenon similar to that found with PP13 immunostainings on first trimester decidual tissue sections (8). Interestingly, using a functional assay and highly sensitive NMR measurements, the native and recombinant PP13 was observed to have weak lysophopholipase activity $(6,9)$ similar to CLC protein. This lysophopholipase activity was also inferred from the release of free fatty acids from cultured primary trophoblasts exposed to PP13 (5). However, it was later revealed that this enzymatic activity of CLC protein is caused by an associated lysophospholipase (10), and further research is required to understand whether the lysophospholipase activity of PP13 is intrinsic or indeed related to an associated protein.

\section{DETAILED STRUCTURAL AND FUNCTIONAL CHARACTERIZATION OF PP13 AS A GALECTIN}

The homology of PP13 to members of the galectin family inspired further structural and functional investigations. Homology modelling based on the "jelly-roll" fold of galectins observed by $\mathrm{X}$-ray crystallography revealed the $3 \mathrm{D}$ model of PP13, which was deposited into the Protein Data Bank (Acc. No.: 1F87) (11). This fold consists of five- and six-stranded $\beta$-sheets
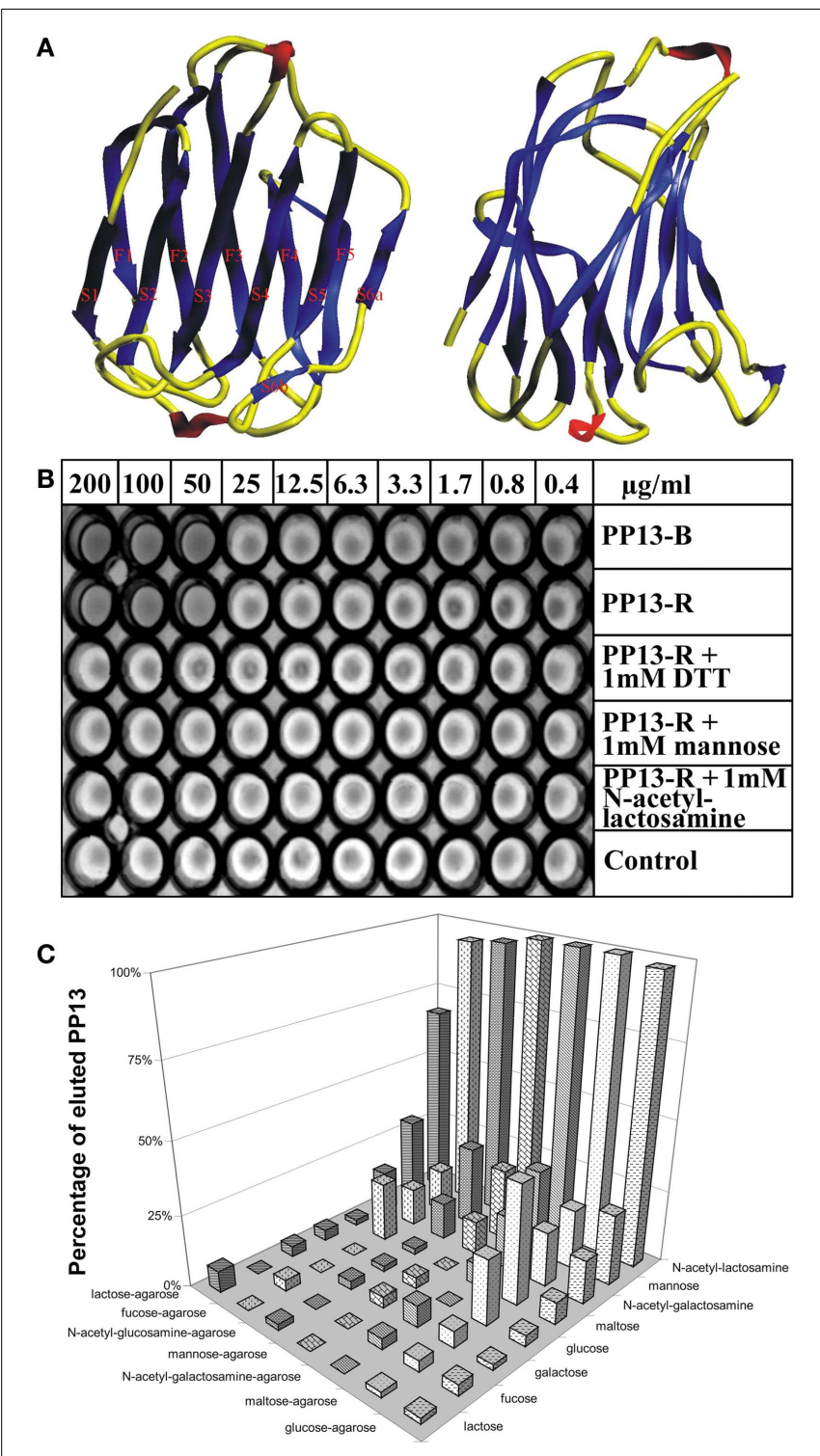

FIGURE 2 |The structural and functional basis for renaming of PP13 as galectin-13. (A) The figure depicts the "jelly-roll" fold of PP13, which consists of five- and six-stranded $\beta$-sheets linked by two $\alpha$-helices. (B) In vitro assays revealed haemagglutinating activity of placenta-purified (PP13-B) and recombinant (PP13-R) PP13. In non-reducing conditions, both PP13-B and PP13-R agglutinated human erythrocytes at $\geq 50 \mu \mathrm{g} / \mathrm{ml}$ protein concentrations. The haemagglutinating ability of PP13- $R$ was inhibited by dithiothreitol or sugars at $\geq 1 \mathrm{mM}$ concentrations. (C) The strength of PP13-R binding to sugar-coupled agarose beads increased from lactose-agarose to glucose-agarose (left to right). PP13 bound to sugar-coupled agarose beads was competitively eluted by sugars (1 M) listed back to front. PP13 had the best eluting capacity (sugar affinity) for $\mathrm{N}$-acetyl-lactosamine, mannose and $\mathrm{N}$-acetyl-galactosamine.

Figure (A) was published in Ref. (11), and Figures (B,C) in Ref. (9). Kind permission for the reuse of figures was obtained from Oxford University Press (A) and John Wiley and Sons (B,C).

linked by two $\alpha$-helices characteristic for "prototype" galectins (Figure 2A). Out of the eight consensus residues in the galectin carbohydrate-recognition domains (CRDs), four identical and 
three conservatively substituted residues were found in PP13. Computational docking simulations showed that the PP13 CRD may bind sugars, e.g. $N$-acetyl-lactosamine and lactose, similar to most galectins (Figure 2A). Since these lines of evidence demonstrated that PP13 is a novel galectin, it was designated as galectin-13 (11).

Galectins constitute a subgroup among the superfamily of lectins, carbohydrate-binding proteins that are important in the regulation of cellular interactions with cells, the extracellular matrix and pathogens. They bind to glycans residing on glycoproteins, glycolipids and other glycoconjugates that constitute a complex array coined the "glycome", which stores orders of magnitude larger biological information than nucleic acids and proteins store. For example, the numbers of 4,096 hexanucleotides and 64 million hexapeptides are far surpassed by the $1.44 \times 10^{15}$ isomer quantity of hexasaccharides (12). Galectins can bind to a diverse set of glycoconjugates, and therefore, they have pleiotropic functions in a variety of key biological processes including signal transduction, cell differentiation, apoptosis, or cell adhesion. Moreover, galectins are positioned at the cross-roads of adaptive and innate immune functions as they are key determinants of acute and chronic inflammation, immune tolerance and host-pathogen interactions (12-18).

Triggered by the recognition that these galectin functions are important determinants of healthy pregnancies (19), the detailed molecular characterization of PP13 allowed greater insight into its function in the placenta during pregnancy. Similar to other galectins, PP13 also hemagglutinated human erythrocytes in vitro (Figure 2B). Furthermore, sugar-binding assays showed the affinity of PP13 for carbohydrates widely expressed in the human placenta (Figure 2C), particularly for $N$-acetyl-lactosamine, mannose and $N$-acetyl-galactosamine (9) as already predicted by molecular modelling (11). Assay performance in reducing conditions decreased the hemagglutinating (Figure 2B) and sugar binding activity of PP13, suggesting that homodimerization of PP13 subunits by disulphide bridges are important for these functions (9).

Through placental immunostaining, PP13 was found in the cytoplasm and brush border membrane of the syncytiotrophoblast. Using affinity chromatography and mass spectrometry, annexin II and beta/gamma actin were identified as ligands of PP13, a finding that was also supported by high colocalization of PP13 with annexin II in the syncytiotrophoblast brush border membrane. These results suggested the galectin-like externalization of PP13 to the cell surface by extracellular vesicles containing actin and annexin II (9). It has to be elucidated whether, similar to other galectins (20), PP13 may bind to glycoconjugates on cell surfaces and form "galectin-glycan lattices" that are important in cellular interactions and signaling.

\section{THE INTERACTIONS OF PP13 WITH ABO BLOOD GROUP ANTIGENS}

As an indirect sign of PP13 binding to glycoconjugates on cell surfaces, placental immunostainings showed PP13 positivity of maternal and fetal erythrocytes, confirming the in vivo erythrocyte-binding of PP13 (21). These results were consistent with the tendency of PP13, similar to other galectins, to bind betagalactosides that are present at terminal positions on $\mathrm{ABO}$ bloodgroup antigens $(9,11,22,23)$. Flow cytometry measurements further demonstrated the binding of PP13 but not its CRDtruncated variant to erythrocytes, proving that PP13 binding is mediated by its CRD (Figure 3A). PP13 binding was similar in intensity to blood group A and O erythrocytes, while PP13 had the weakest binding intensity to blood group $\mathrm{B}$ and the strongest binding intensity to blood group $\mathrm{AB}$ erythrocytes (Figure 3A). Similar to other galectins $(24,25), \mathrm{PP} 13$ binding to various ABO blood group erythrocytes changed dynamically with increasing PP13 concentrations (Figure 3C).

Computational studies have indicated that the structural basis for ABO blood group antigen binding includes the following: (1) three out of four residues in the core galectin CRD involved in disaccharide-binding are conserved in PP13 (11, 23); (2) PP13 has a similar "B-site" involved in ABO antigen binding as human galectins that exhibit $\mathrm{ABO}$ blood group antigen binding $(21,25)$; and (3) PP13 accommodates blood group $\mathrm{H}$ trisaccharide in its CRD similar to a fungal galectin's CRD (21) (Figure 3B).

It is interesting to note that $\mathrm{ABO}$ blood group antigens are oligosaccharides attached to cell-surface glycoconjugates on epithelia, endothelia and erythrocytes, which might have been evolutionarily advantageous in conferring resistance against certain pathogens (26). The gene encoding for the enzymes that catalyze the transfer of these oligosaccharides to cell-surface glycoconjugates emerged in primates $(22,27)$. If the evolution of the ABO blood group system and genes encoding for PP13 and closely related galectins was somehow associated, that would suggest a potential functional relevance of $\mathrm{PP} 13$ binding to $\mathrm{ABO}$ blood group antigens.

\section{THE EVOLUTION AND HUMAN DISEASE-RELATED POLYMORPHISMS OF LGALS13 EVOLUTIONARY ANALYSES OF GENES ENCODING FOR PP13 AND
CLOSELY RELATED GALECTINS}

An evolutionary study presented compelling evidence that a cluster of galectin genes, including LGALS13 that encodes PP13, emerged on chromosome 19 in anthropoid primates, which differ from other primates by having larger brains and longer gestations (23). The analysis of this galectin cluster in the available genome assemblies revealed frequent gene duplication, inversion and deletion events characteristic of repeat-mediated "birth-and-death" evolution, a process that leads to novel phenotypes in species adapting to their changing environment (28). Detailed analysis showed that transposable long interspersed nuclear elements (LINEs) were positioned at the majority of boundaries of large inversions and gene duplication units, suggesting that LINEs had mediated the rearrangements within this cluster. Genes in this cluster have fourexon structures as other "prototype" galectin genes. Of the two major clades in the cluster, one contains genes with predominant placental expression including LGALS13 and related pseudogenes. Of note, LGALS13 was only found in Old World monkeys and apes. Sequence analyses of 24 newly determined sequences and 69 annotated sequences in 10 anthropoid species indicated functional diversification among PP13 and related galectins during evolution as can be inferred from the amino acid replacements in their CRDs (23).

Sequence comparison showed a strong conservation of more than half of the residues of PP13 and cluster galectins 

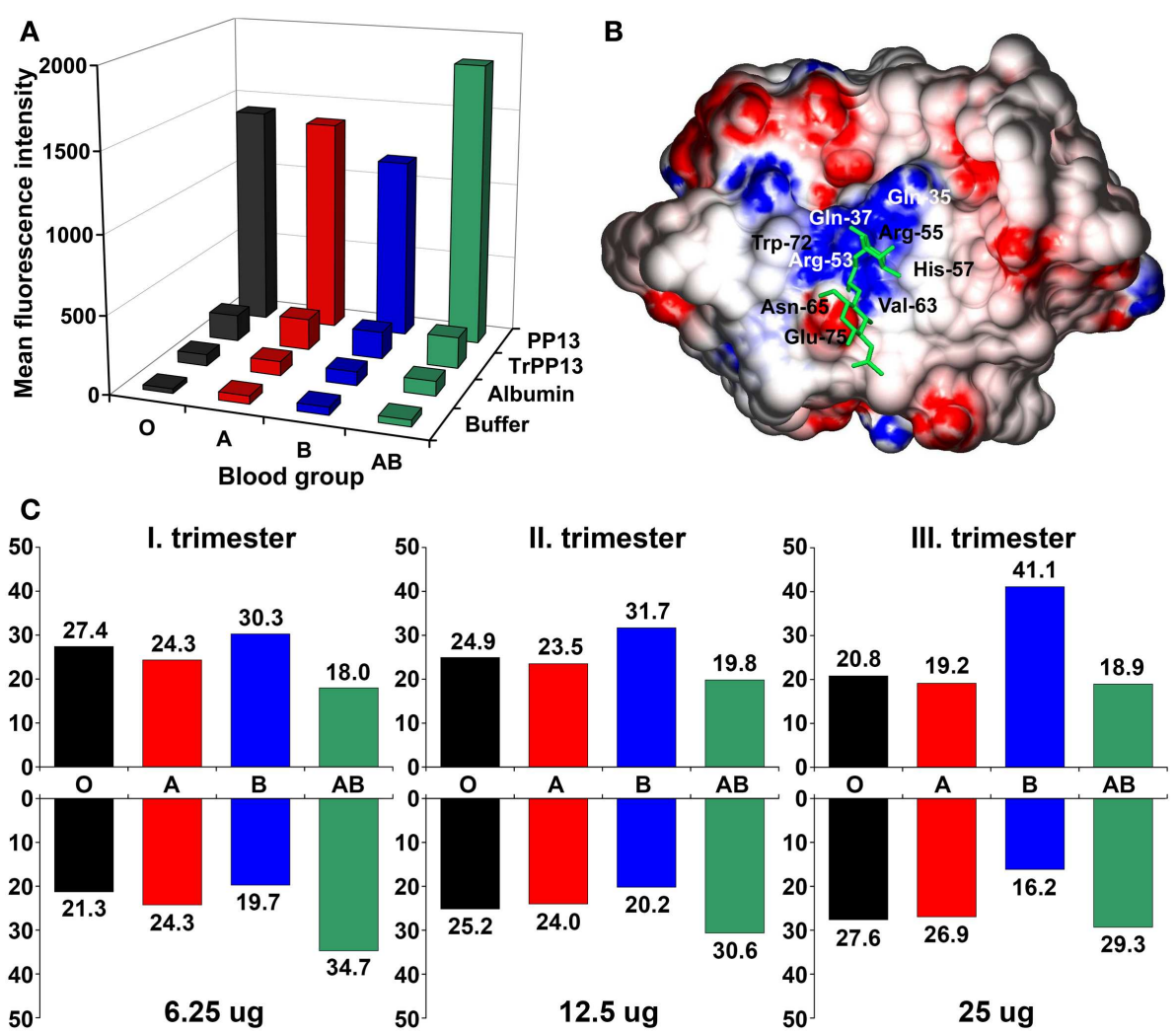

FIGURE 3 | The differential binding of PP13 to ABO blood group antigens in vitro and in vivo. (A) Flow cytometry showed that recombinant PP13 binding to erythrocytes was specific and mediated by its carbohydraterecognition domain (CRD) since recombinant truncated PP13 (TrPP13) bound negligibly similar to bovine serum albumin (BSA). PP13 had the strongest affinity to blood group $A B$ erythrocytes and weakest affinity to blood group $B$ erythrocytes. (B) Surface representation of PP13 complexed with blood group $\mathrm{H}$ trisaccharide (green). Blue and red colors indicate positive and negative electrostatic potentials on the molecular surface, respectively. The binding groove of the CRD contains a central positive channel flanked by negative regions. (C) The relative binding of PP13 (lower panel) to different ABO blood group erythrocytes dynamically changed and inversely mirrored the relative serum PP13 concentrations (upper panel) in women with different ABO blood groups with advancing gestation from the first to third trimesters. All figures were published in Ref. (21). Kind permission for the reuse of figures was obtained from the Public Library of Science. predominantly located in the protein cores that determine their overall structure, whereas residues on their surface, especially in the loop regions, have undergone rapid evolution (23) (Figure 4A). From the eight conserved residues in the galectin CRD, four (positions: 53, 65, 72, and 75) that are key in the overall sugar binding form a pocket in one side of the CRD and were under purifying selection in PP13 and cluster galectins. The other four residues (positions: 55, 57, 63, and 77) on the opposite side of the CRD had more variability among cluster galectins, with frequent replacements in several lineages following gene duplications including K>T77 in PP13 (Figure 4B). As these latter four residues are crucial for galactose or glucose binding, the structural differences might have resulted in differing functions between PP13 and other cluster galectins. Indeed, functional experiments with human recombinant PP13 and five other galectins proved the different sugar-binding profiles of these investigated proteins (23).

A large number of pseudogenes in the studied species were found in the cluster (23). These emerged by the deletion of exons, mutations of the exon-intron boundaries, and by the introduction of one or more in-frame premature stop codons. As a striking observation, 18 out of the identified 38 pseudogene variants contained the "163C $>$ T" DNA variant leading to the introduction of a premature stop codon at the site encoding residue 55, which may result in truncated proteins of 54 amino acids that lack the entire CRD. In fact, functional experiments proved that this " $163 \mathrm{C}>\mathrm{T}$ " DNA variant results in the expression of a truncated PP13 that cannot bind carbohydrates (23). The question why nature utilized the same process to silence so many galectin genes in certain lineages, including LGALS13 in baboon, Bornean orangutan and Sumatran orangutan, remains unanswered.

\section{DNA VARIANTS IN HUMAN LGALS13}

Somewhat related to evolutionary selection, a total of 933 LGALS13 DNA variants have been already identified in the genomes of 1,092 individuals from 14 populations by the " 1000

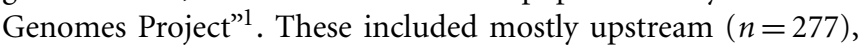
downstream $(n=261)$ or intron $(n=240)$ variants. Besides these, non-coding transcript $(n=98)$ or exon $(n=56)$ variants and missense variants $(n=56)$ were frequently detected. Nevertheless, the

\footnotetext{
${ }^{1}$ www.1000genomes.org
} 

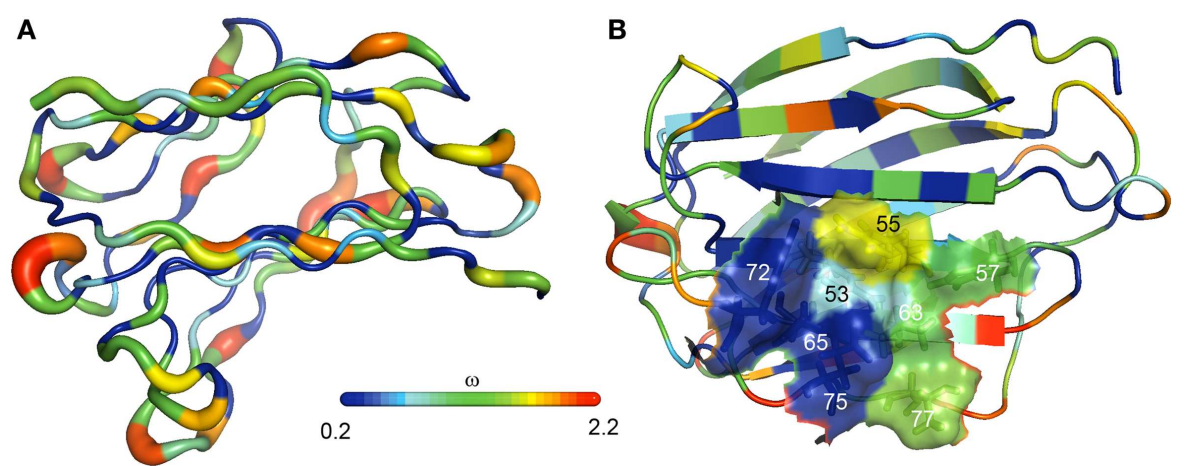

FIGURE 4 |The evolution of PP13 and closely related galectin genes in the chromosome 19 cluster. (A) Evolutionary changes leading to structural diversification in chromosome 19 cluster galectins are depicted on the molecular backbone of PP13 (left). The width and color of the ribbon varies in proportion with site-specific $\omega$ values $\left(d_{N} / d_{s} ; \omega<1\right.$, purifying selection; $\omega>1$, positive selection) for chromosome 19 cluster galectins. $\omega$, indicated by the color spectrum on the bar, is the smallest along $\beta$-strands and highest in loop regions. (B) The same color coding shows that four residues in the PP13 CRD (residues: 53, 65, 72, 75) have been conserved in chromosome 19 cluster galectins, while the other four residues on the opposite side of the CRD (residues: 55, 57, 63, 77) show more evolutionary changes among these galectins.
"1000 Genomes Project" has not provided information regarding the association of LGALS13 DNA variants with disease susceptibility. In search of LGALS13 DNA polymorphisms by targeted genotyping studies, the association of certain LGALS13 DNA variants with severe complications of pregnancy has been identified. These studies utilized whole blood DNA samples obtained from pregnant women and their neonates in a South African cohort of the Black and Coloured population, and the following DNA variants were revealed for LGALS13: (1) variants in Exon 3 including single nucleotide polymorphisms (SNPs) and a single nucleotide deletion, which latter causes a frame-shift in the open reading frame, leading to the formation of a premature stop codon and a truncated protein (221delT); (2) SNPs in Introns 2 and 3 including an intron boundary polymorphism that is associated with alternative splicing and the deletion of Exon 2; and (3) an SNP in the promoter region (29-34).

Of interest, in a prospective cohort of 450 low-risk primigravid women of Black and Coloured origin, carrying the naturally occurring "221delT" mutation conferred a 2.27-fold relative risk for preterm labor (34). The frequency of heterozygous carriers of this mutation was higher in the group of women with preterm preeclampsia $(5.7 \%)$ than in controls $(2.4 \%)$, and no individuals were found to be homozygous. In another study conducted on the same population, there was a significant association for this mutation and preeclampsia, particularly among Coloured women (33). These results suggest that the placental expression of a functionally impaired, truncated PP13 may put women at increased risk for severe pregnancy complications. However, so far no polypeptide derived from the " 221 delT" DNA polymorphism could be identified in placental or body fluid samples, most likely due to the rapid degradation or insufficient immunodetection of such a protein because of the anticipated major misfolding (35).

The “-98A/C" promoter polymorphism was also associated with the risk of preeclampsia $(31,33,34)$. In a prospective cohort of low-risk pregnant women, controls were in the Hardy-Weinberg equilibrium, while cases deviated from that, and the heterozygous A/C genotype appeared to be protective against preeclampsia
(31). Another study comprising the same population found a significant difference between "-98A/C" genotype distributions in patients with placental abruption and controls among Coloured women (33). These results suggest that the “-98A/C" promoter polymorphism may negatively affect LGALS13 expression and PP13 functions.

\section{THE EXPRESSION PATTERN OF PP13 IN HUMANS WIDE-SCALE EXPRESSION PROFILING OF PP13 IN HUMAN TISSUES}

Besides the studies on LGALS13 DNA variants, the investigations on the expression patterns of PP13 have revealed interesting insights. The study describing the cloning of PP13 also presented compelling evidence for the predominant placental expression of PP13 in the human body (6). In fact, the expression profiling of human adult and fetal, normal and tumorous tissues by Western blot (26 tissues) and Northern blot (16 tissues) detected a $16 \mathrm{kDa}$ PP13 immunopositive band in extracts of human term placentas, and unique placental PP13 mRNA expression, respectively. These findings were supported by GenBank evidence of only placental expressed sequence tags for LGALS13. Later, the widescale expression profiling of LGALS13 and related chromosome 19 cluster galectin genes using qRT-PCR on a human 48-tissue cDNA panel confirmed the predominant placental expression of LGALS13 (Figure 5A) (23).

\section{PLACENTAL EXPRESSION PROFILING OF PP13 IN NORMAL PREGNANCIES}

In human villous placental tissues at term, immunohistochemistry and immunofluorescence consistently found predominant PP13 positivity of the syncytiotrophoblast and villous capillary endothelium but not the cytotrophoblasts $(8,9,21,23,36,37)$. In situ hybridization (23) detected PP13 mRNA expression in the same placental cells, further confirming the specificity of the immunostainings (Figure 5B). The same PP13 expression pattern was found in the placentas of Old World monkeys, suggesting the conservation of PP13 expression during evolution (Figure 5C). Moreover, in situ hybridization revealed LGALS13 expression in the amnion 


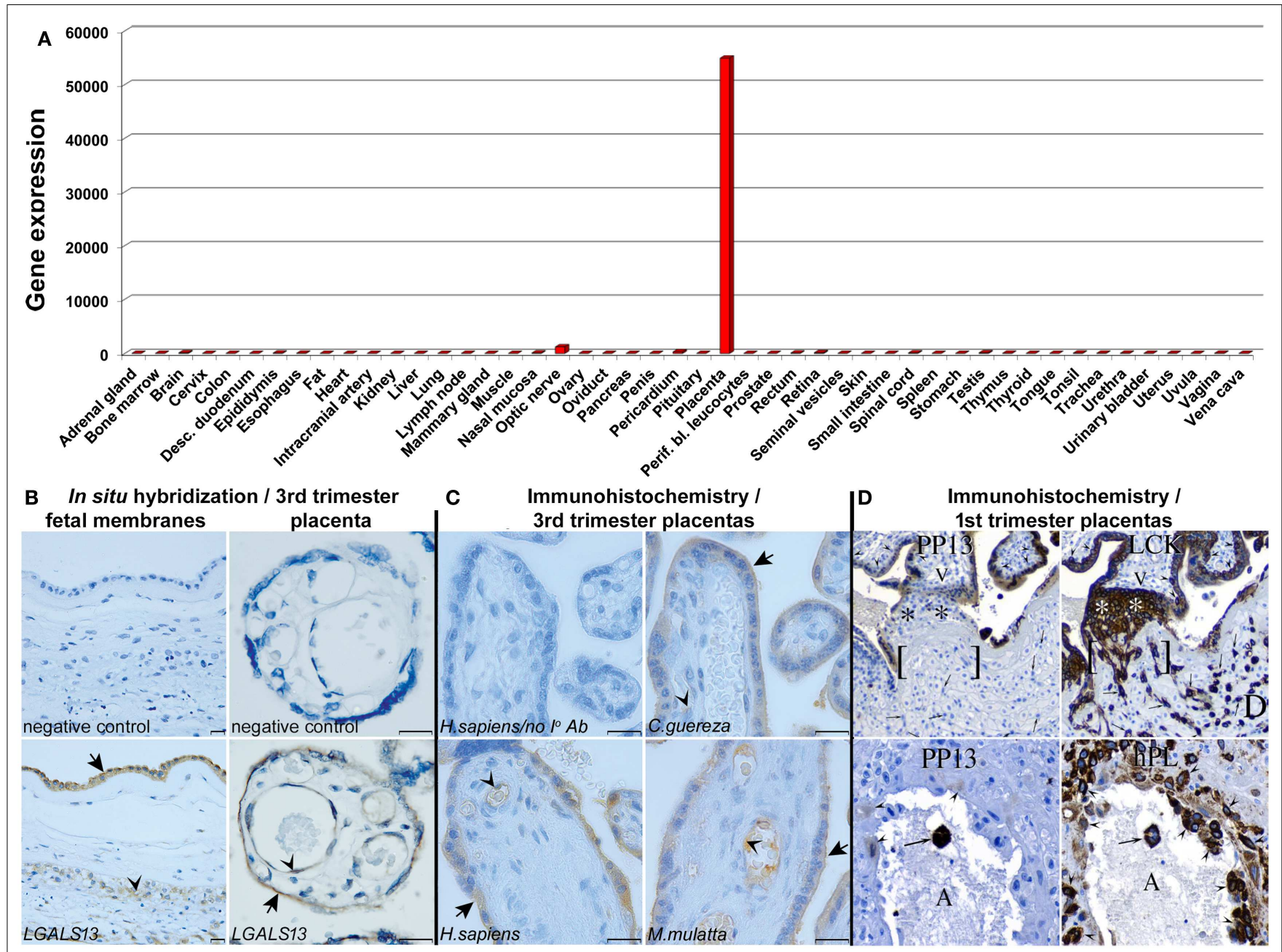

FIGURE 5 | PP13 expression profiling. (A) qRT-PCR on a human 48-tissue CDNA panel uncovered that $L G A L S 13$ is predominantly expressed by the placenta. The y axis shows gene expression levels $\left[2^{(-\Delta \mathrm{Ct})}\right]$. (B) In situ hybridization revealed LGALS13 expression in the amnion (arrow) and chorionic trophoblasts (arrowhead) in the fetal membranes in normal term pregnancy (left). In normal term placenta, LGAL13 is predominantly expressed by the syncytiotrophoblast (arrow) and endothelium (arrowhead) (right). Scale bars: $20 \mu \mathrm{m}$. (C) PP13 immunostaining is conserved in the syncytiotrophoblast, its apical membrane (arrows), and the endothelia (arrowheads) of human and anthropoid primate placentas. (Scale bars: $20 \mu \mathrm{m}$.) (D) (Upper panel) Serial sections of a 15 week junctional complex stained for PP13 and low molecular weight cytokeratin (LCK). LCK immunostained epithelial cells, including cytotrophoblasts (arrowheads), anchoring trophoblasts $(*)$, early infiltrating trophoblasts [ ], and invasive trophoblasts (arrows) in the decidua (D). Mesenchymal villous core cells (V) and decidual cells were negative. PP13 immunostaining was found in the syncytiotrophoblast. The cytotrophoblasts (arrowheads), anchoring trophoblasts $(*)$, early infiltrating trophoblasts [ ], and the invasive trophoblasts (arrows) in the decidua (D) were negative. (Lower panel) Serial sections of 8 week maternal spiral arterioles immunostained for PP13 and human placental lactogen (hPL). All the decidual invasive, intravascular and endovascular trophoblasts (arrowheads), and a single luminal (A) syncytiotrophoblast (arrow) were stained for $\mathrm{hPL}$. The monoclonal anti-PP13 antibody did not stain decidual invasive trophoblasts, lightly stained endovascular trophoblasts (arrowheads), and it intensely stained luminal syncytiotrophoblasts (arrow). Figure (A) represents data published in Ref. (23). Figures (B,C) were published in Ref. (23). Figure (D) was published in Ref. (8). Kind permission for the reuse of the figures was obtained from the National Academy of Sciences of the United States of America (A-C) and SAGE US (D). and chorionic trophoblasts in the fetal membranes. These findings showed PP13 expression predominantly in locations where maternal-fetal immune interactions occur.

In the first trimester, PP13 was immunolocalized to the syncytiotrophoblast and multinucleated luminal trophoblasts within converted decidual spiral arterioles (8). Villous cytotrophoblasts and invasive extravillous trophoblasts in the anchoring trophoblastic columns were immunonegative (Figure 5D). The syncytiotrophoblastic staining intensity declined with gestational age, being the strongest between 6 to 8 weeks of gestation. This study also confirmed previous findings in term placental tissues on predominant, diffuse cytoplasmic and also nuclear immunopositivity of the syncytiotrophoblast.

\section{EXPRESSION PROFILING OF PP13 DURING VILLOUS TROPHOBLAST DIFFERENTIATION AND FUSION}

Based on this immunohistochemical evidence, it was hypothesized that PP13 expression is related to the biochemical and 
morphological differentiation and syncytialization of the villous trophoblast (36). These processes are primarily governed by cyclic adenosine monophosphate (cAMP) and protein kinase A (PKA), which regulate the resetting of the transcriptional program during the shift from cytotrophoblast into the syncytiotrophoblast $(38-40)$. The resulting unique transcriptome of the syncytiotrophoblast (41) controls the production of placental hormones, immune proteins and other proteins predominantly expressed by the placenta, which support pregnancy. Besides the exchange of feto-maternal gas, nutrients and waste, and the hormonal regulation of fetal development, the syncytiotrophoblast is also active in generating immune tolerance between the mother and her semi-allogeneic fetus $(2,42,43)$.

In vitro assays with trophoblast-like BeWo cells demonstrated that indeed LGALS13 expression is related to trophoblast fusion and syncytium formation induced by the cAMP-analogue Forskolin, and that a PKA inhibitor could block BeWo cell syncytialization and LGALS13 expression (44). A recent study confirmed these findings in BeWo cells, and demonstrated the syncytialization and differentiation-related LGALS13 expression in primary villous trophoblasts (45). The evolutionary and functional investigations of the trophoblastic regulatory mechanisms of LGALS13 expression showed that promoter evolution and the insertion of an anthropoid-specific LINE element into the $5^{\prime}$ untranslated region (UTR) of an ancestral gene introduced binding sites for several transcription factors (e.g. ESRRG) key in villous trophoblastic gene expression, leading to the gain of placental expression of LGALS13 and related chromosome 19 cluster galectin genes (43, 45). Glial cell missing-1 (GCM1), the transcription factor that governs villous trophoblast fusion and syncytialization (46), was shown to facilitate the expression of ESRRG and other key villous trophoblastic transcription factors, and thus, to indirectly promote the placental expression of LGALS13 and cluster galectin genes. In addition, DNA methylation was also observed to regulate developmental expression of LGALS13 and cluster galectin genes (45).

\section{PLACENTAL ASPECTS OF PREECLAMPSIA}

It is important that the impairment of villous trophoblast syncytialization characterized by the decreased trophoblastic expression of GCM1 and syncytin-1, a fusogenic protein regulated by GCM1, has been observed in preeclampsia $(47,48)$, an obstetrical syndrome originating from impaired early placentation $(49,50)$. Preeclampsia is diagnosed by new-onset hypertension and proteinuria after 20 weeks of gestation, and it is a major cause of maternal, fetal and neonatal morbidity and mortality (51). Moreover, this syndrome consists of various subtypes defined by gestational age (e.g.: early-onset: $<34$ th weeks; preterm: $<37$ weeks; and term: $\geq 37$ weeks) $(52,53)$. Early-onset and preterm preeclampsia are severe subtypes of the disease that require premature delivery and are more often associated with intrauterine growth restriction (IUGR), hemolysis, elevated liver enzymes, and low platelet count (HELLP) syndrome, and fetal death, while term preeclampsia may be severe or mild in its clinical presentation (51-55). Although the molecular pathways of preeclampsia are incompletely understood, it appears to be associated with impaired placentation as the only definite therapy of preeclampsia is still the delivery of the fetus and the removal of the placenta $(50,51,53)$. It is also evident that heterogeneous causes can trigger early placental pathologic events, and that these are followed by the onset of the terminal pathway of preeclampsia in a later stage, leading to the subsequent clinical onset of the symptoms $(50,51,56)$.

Several studies providing histopathologic or transcriptomic evidence have suggested that the placental pathogenesis of preeclampsia may differ in its subtypes as more pronounced differences could be observed in early-onset than late-onset preeclampsia when compared to gestational age-matched controls (57-61). In line with these findings, the extent of histopathologic changes in the placental bed was most extensive in early-onset preeclampsia, especially in cases associated with IUGR. These abnormal findings were consistent with impaired trophoblast invasion into the uterine tissues and the consequent abnormal remodelling of the maternal spiral arterioles, placental pathologic events that occur in the first trimester $(62,63)$.

Previously it was thought that impaired early placentation is associated with placental hypoxia (64); however, it has recently become evident that the resulting fluctuation in uterine blood supply leads to placental ischemic injury, causing oxidative stress, pro-inflammatory conditions, and apoptosis (65-67). In response, the placenta expresses and releases increased amounts of antiangiogenic factors, pro-inflammatory cytokines and aponecrotic syncytiotrophoblast microvesicles. The latter might induce maternal anti-angiogenic and exaggerated systemic pro-inflammatory states, hypertension and proteinuria $(50,51,53,66,68-70)$.

\section{DECREASED PLACENTAL PP13 EXPRESSION IN PREECLAMPSIA}

In this context, LGALS13 expression was found to be downregulated in villous placental tissues in preeclampsia. This was first described for preterm preeclampsia compared to gestational agematched controls at the time of disease, and this phenomenon was suggested to be associated with problems in trophoblast syncytialization (36) (Figures 6A,B). Since then, other studies confirmed these findings in the third trimester, including one that investigated placental LGALS13 expression at the time of disease (71) and another that looked for syncytiotrophoblastic LGALS13 expression in laser captured specimens in the first trimester (72). The latter study detected decreased LGALS13 expression in the syncytiotrophoblast from chorionic villus samples obtained at 11 weeks of gestation in women who subsequently developed preeclampsia compared to controls. Such first trimester down-regulation of placental LGALS13 expression may be one of the earliest pathological indications for the subsequent development of preeclampsia.

A recent study has revealed the possible molecular mechanisms leading to decreased placental LGALS13 expression in women with severe preterm preeclampsia. It was found that in this subform of preeclampsia there is a decreased placental expression of GCM1 and $E S R R G$, genes encoding transcription factors that regulate trophoblastic LGALS13 expression (45). Moreover, functional experiments showed that the knock-down of GCM1 in BeWo cells led to the down-regulation of ESRRG and other transcription factors that regulate LGALS13 expression. Accordingly, it was concluded that there is a decreased GCM1-mediated trophoblast fusion and trophoblastic gene expression in severe preterm preeclampsia that leads to the down-regulation of LGALS13. Furthermore, 


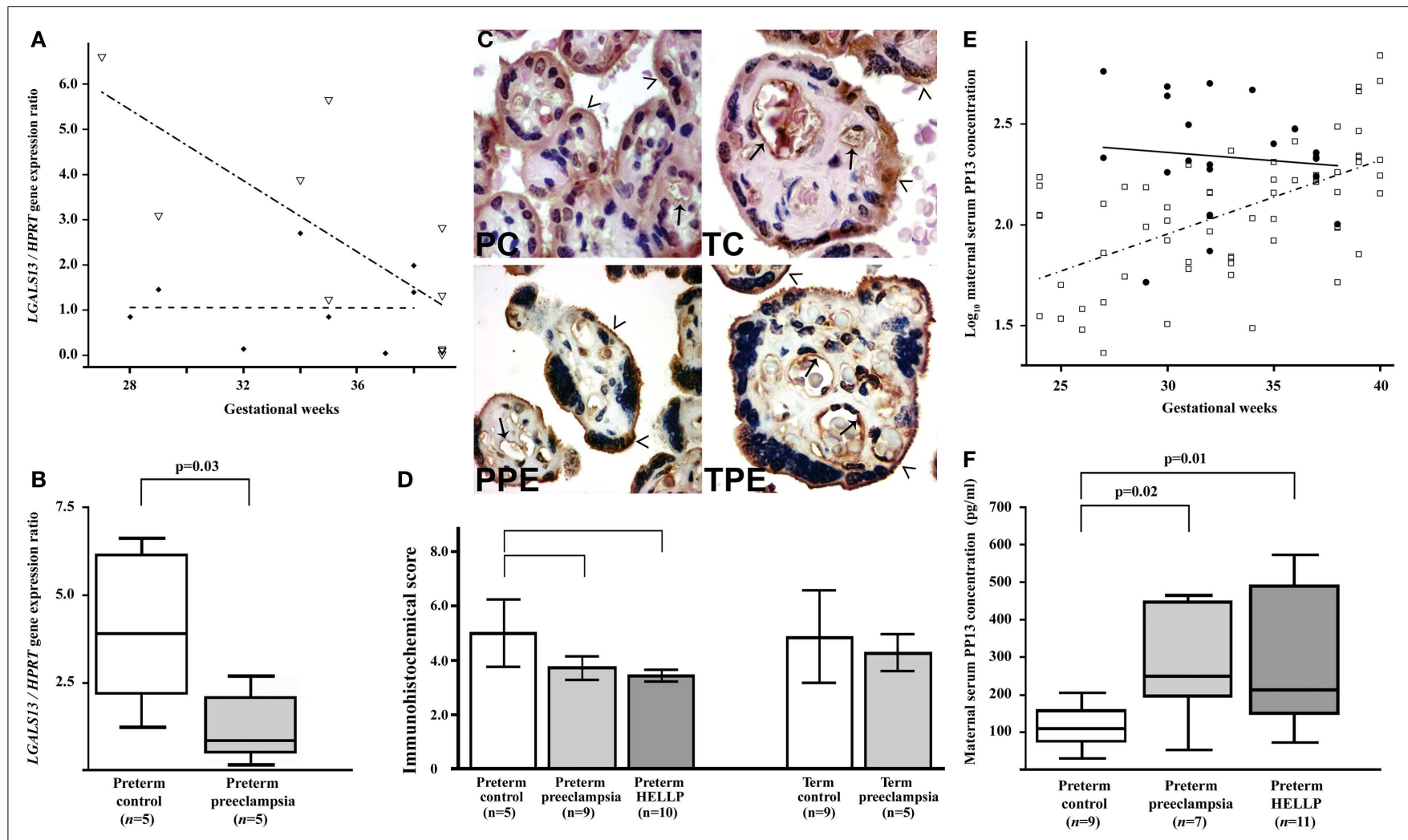

FIGURE 6 | Decreased placental LGALS13 expression and increased trophoblastic PP13 shedding in preterm preeclampsia. (A) Relative LGALS13 expression decreases with advancing gestational age in controls (open triangles), while it is constantly low in patients with preeclampsia (diamonds). (B) Relative LGALS13 expression is lower in women with preterm preeclampsia than in controls. (C) Syncytiotrophoblastic PP13 immunostaining is decreased in preterm preeclampsia compared to controls. PC: preterm control, $35 \mathrm{GW}$ (weeks of gestation); TC: term control, GW38; PPE: preterm preeclampsia, GW29; TPE: term preeclampsia, GW37. The endothelium (arrows) is also PP13 immunopositive in all sections. The microvillous membrane (open arrowheads) stains moderately for PP13 in controls, while it is strongly PP13 immunopositive in preeclampsia. 500x (left) or $700 \times$ (right) magnification. (D) The immunohistochemical score of the syncytiotrophoblast is higher in preterm controls than in preterm preeclampsia, with or without HELLP syndrome, while it is not different between cases and controls at term. (E) Maternal serum $\log _{10}$ PP13 concentrations increase as a function of gestational age in control women (open rectangle), while these do not correlate with gestational age in patients with preeclampsia (filled circle). The regression line for $\log _{10}$ PP13 concentrations is significantly different in the two groups. (F) Median maternal serum PP13 concentrations are higher in women with preterm preeclampsia, with or without HELLP syndrome, than in controls. All the figures were published in Ref. (36). Kind permission for the reuse of figures was obtained from Springer Science+Business Media. the differential methylation of LGALS13 was also found in the villous trophoblast in preterm preeclampsia, which may interfere with LGALS13 expression, suggesting that potential additional disease-mechanisms may account for the trophoblastic pathology in preterm preeclampsia (45).

\section{ALTERED PLACENTAL LOCALIZATION AND INCREASED SHEDDING OF PP13 IN PREECLAMPSIA}

In accord with gene expression data, immunostainings revealed that cytoplasmic PP13 positivity of the syncytiotrophoblast was weaker in preeclampsia compared to controls, particularly in preterm cases. Similar changes were also observed at the time of disease in preterm HELLP syndrome (36) (Figures 6C,D). Paradoxically, PP13 immunostaining of the syncytiotrophoblast microvillous membrane was stronger in preeclampsia and HELLP syndrome compared to controls (Figures 6C, 7A). Syncytial cytoplasmic protrusions and membrane microvesicles shed from the syncytiotrophoblast stained strongly for PP13 in preeclampsia
(Figure 7A). It was suggested that the increased release of PP13 positive microvesicles from the syncytiotrophoblast may lead to elevated maternal serum PP13 concentrations in preterm preeclampsia and HELLP syndrome before or at the time when the clinical symptoms of preeclampsia appear (Figures 6E,F) $(36,37)$.

The subcellular redistribution of PP13 in the syncytiotrophoblast was further observed by confocal imaging of placental samples from patients with preeclampsia and HELLP syndrome compared to gestational age-matched controls (73). In all study groups, PP13 highly colocalized with placental alkaline phosphatase, a glycophosphatidylinositol-anchored lipid raft-resident protein. However, there was also a high degree of colocalization of PP13 with CD71, a non-raft plasma membrane protein, which decreased in preterm preeclampsia and HELLP syndrome. In contrast, the colocalization of PP13 with cytoskeletal actin, a protein earlier found to bind to PP13 with high affinity (9), was increased in all patient groups compared to controls. These results indicated that the translocation of PP13 to the juxta-membrane region of 


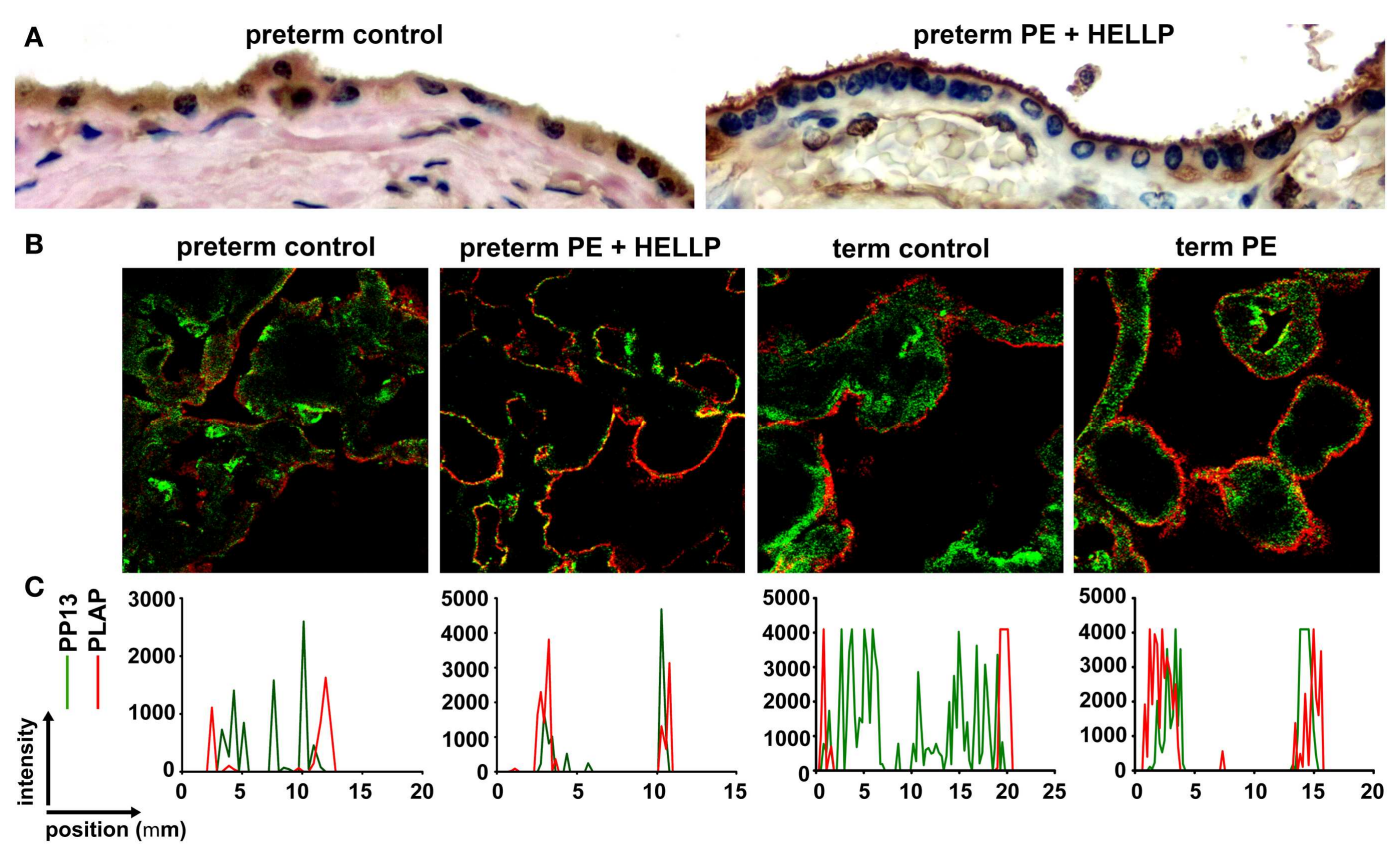

FIGURE 7 | Subcellular relocalization of PP13 in preeclampsia and HELLP syndrome. (A) Representative images show uniformly moderate cytoplasmic and brush border membrane PP13 immunostaining of the syncytiotrophoblast in a preterm control placenta (left), while its weak cytoplasmic and strong membrane immunostaining in a placenta from a woman with preterm preeclampsia (PE) associated with HELLP syndrome (right). Cytoplasm protrusions, membrane blebs and shed membrane microvesicles immunostained intensely for PP13 (right). $800 \mathrm{x}$

magnification. (B) Representative confocal images show the subcellular relocalization of PP13 (green) near to placental alkaline phosphatase (PLAP) immunopositive (red) lipid rafts in the juxtamembrane regions of the syncytiotrophoblast in term preeclampsia and preterm preeclampsia associated with HELLP syndrome compared to controls. (C) Line scan intensity distributions of PP13 and PLAP in representative confocal images shown in subfigure (B). Figure (A) was published in Ref. (36).

Figures (B,C) were published in Ref. (73). Kind permission for the reuse of the figures was obtained from Springer Science+Business Media (A) and Elsevier (B,C). the syncytiotrophoblast in preeclampsia and HELLP syndrome is associated with actin (Figures 7B,C) (73). Supporting these observations in the placenta, subsequent in vitro experiments revealed that Latrunculin B, a selective blocker of actin polymerization, decreased PP13 release from BeWo cells and led to its intracellular accumulation (Figure 8A) (73).

This result may also explain how PP13 is released from the syncytiotrophoblast since the actin cytoskeleton and associated motor proteins drive intracellular and plasma membrane trafficking amongst a wide variety of cellular processes $(74,75)$. In this regard, galectins predominantly utilize unconventional trafficking routes, either vesicular or direct translocational, avoiding the endoplasmic reticulum (ER) and Golgi apparatus, since they are synthetized on free ribosomes and lack an $N$-terminal signal sequence for the translocation to the ER/Golgi system (76-78). However, other vesicular transport mechanisms for PP13 cannot be excluded, such as the "kiss and run" exocytosis, which was described for many hormones and neurotransmitters and was proved to be an actin- and calcium-dependent process $(79,80)$.

The role of actin cytoskeleton in the release of extracellular vesicles (EV; e.g. microvesicles/microparticles and exosomes), which also carry various galectins, has also been demonstrated (81-83). In addition, annexin II, another protein that specifically bound to PP13 (9), has also been found in various types of EVs along with actin $(84,85)$. Similar to galectin-9, which was shown to be associated with many different types of EV fractions (86), PP13 may also translocate with different EVs through the syncytiotrophoblast membrane. This type of release is supported by evidence on the PP13 release from BeWo cells mediated by exosomes (73) and the observed PP13 immunopositivity of microvillous membrane microvesicles shed from the syncytiotrophoblast (36).

\section{THE ROLE OF CALCIUM AND ISCHEMIA IN TROPHOBLASTIC PP13 RELEASE}

Recent in vitro experiments with BeWo cells transfected with LGALS13 to enable high PP13 expression (73) also showed an increased PP13 release from calcium ionophore-treated cells, evidenced by decreased cellular PP13 content and elevated amounts of PP13 in cell culture supernatants (Figure 8B). This finding is in accord with a previous report showing that galectin-3 is secreted by exosomes from monocytes upon calcium ionophore treatment (87). Calcium serves as a ubiquitous second messenger responsible for controlling numerous cellular processes including exosome secretion (88). Since calcium regulates the actin cytoskeleton at multiple levels including the organization of actin monomers into actin polymers and the super-organization of actin polymers into a filamentous network (89), it is not surprising that stimuli resulting in the elevation of intracellular calcium concentration can induce microvesiculation and membrane shedding of exposed cells $(90,91)$. As a mechanism, the dynamics of actin assembly and 

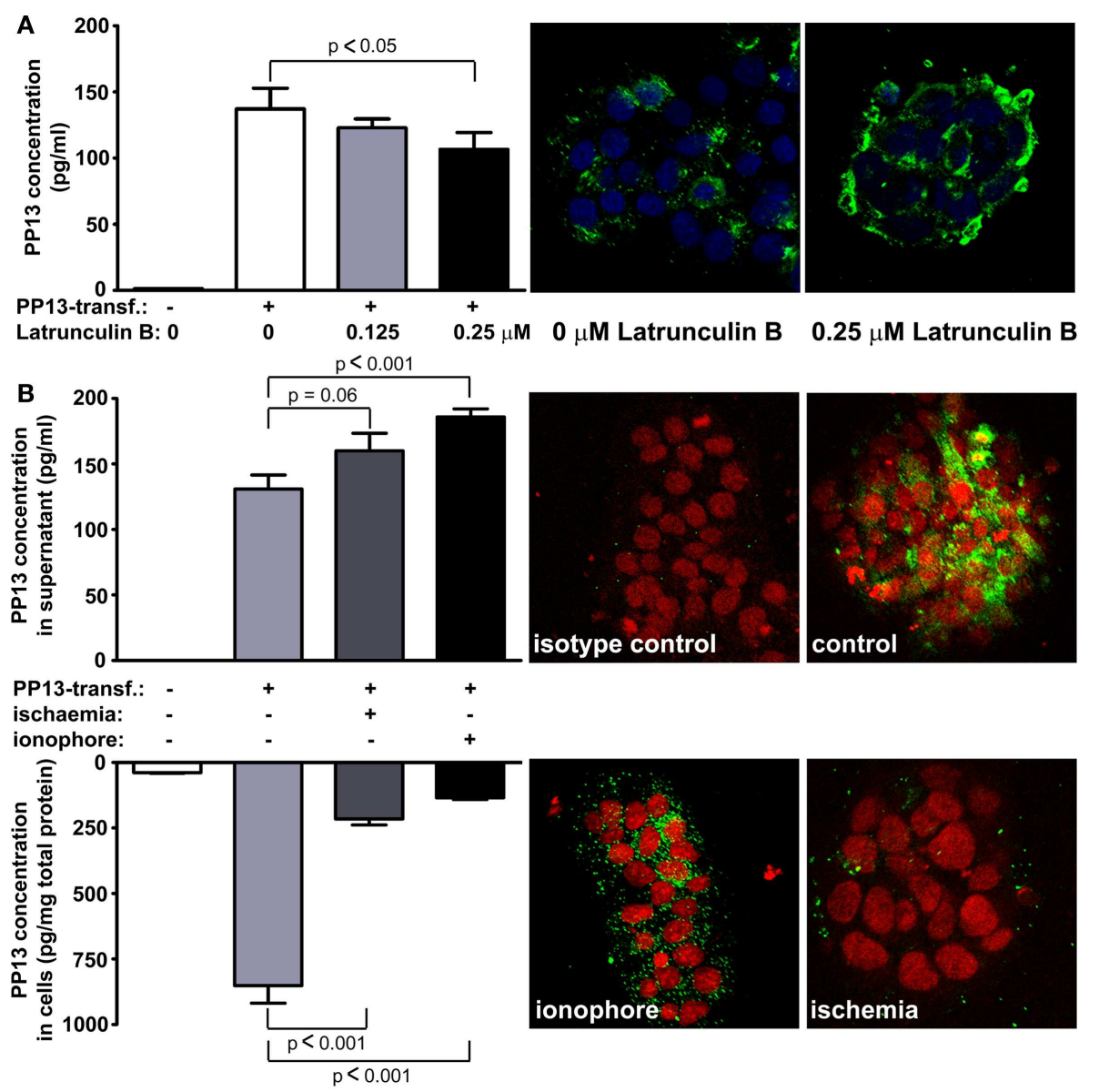

FIGURE 8 | Blocking of actin polymerization inhibits while calcium and ischemia promotes trophoblastic PP13 release. (A) PP13 content of BeWo cell culture supernatants of non-transfected controls, as well as LGALS13-transfected, untreated or Latrunculin B-treated cells were measured by ELISA (left). LGALS13-transfected, untreated or Latrunculin B-treated cells were stained with anti-PP13 (green) and nuclei were counterstained with DRAQ5 (blue) followed by confocal microscopic analysis (right; 40x magnifications). The disruption of the actin cytoskeleton with Latrunculin B treatment decreased PP13 release from BeWo cells. (B) LGALS13-transfected BeWo cells were treated with calcium ionophore to increase intracellular calcium level, or kept under ischemic stress to mimic placental milieu in preterm preeclampsia. (Left) PP13 content of BeWo cells and cell culture supernatants of non-transfected controls, as well as LGALS13-transfected, untreated, calcium ionophore-treated or ischemia exposed cells were measured by ELISA. (Left) Representative confocal images of LGALS13-transfected control, calcium ionophore-treated or ischemia exposed BeWo cells immunostained with monoclonal anti-PP13 antibody (green) and counterstained with DRAQ5 (red) nuclei dye. Either ionophore treatment or ischemia induced the release of PP13 from BeWo cells. Figures were published in Ref. (73). Kind permission for the reuse and modification of the figures was obtained from Elsevier. disassembly is regulated by certain actin-binding proteins such as annexin II in a calcium-dependent manner (92-96).

The release of PP13 from BeWo cells appears to be similar to the in vivo release when comparing the effect of calcium ionophores and ischemic stress (Figure 8B) (73). Ischemic stress of the placenta is a major component of the pathophysiology of preterm preeclampsia (97). In accord, higher PP13 release was observed in placental villous tissue explants obtained from women with preeclampsia compared to gestational age-matched controls in the third trimester (98). A possible explanation is that ischemic stress causes elevation in intracellular calcium levels, which leads to actin depolymerization supported by findings of separate studies $(99,100)$. All of these results indicate that different kind of actin- and calcium-dependent release mechanisms exist side by side for PP13, and most probably the dominant sort depends on the cell type and also on the nature of the received stimuli.

As a functional aspect of the increased PP13 release from the placenta in preeclampsia, ischemic and other stress conditions pose danger to the organism, which is signaled to the immune system by endogenous danger signals called "alarmins" $(101,102)$. Indeed, "danger signals" in the placenta have also been proposed to create an abnormal placental cytokine milieu and link the activation of the innate immune system and preeclampsia (8, 103-105). In this context, some galectins with cytokine-like properties (106, 107) may act as alarmins, since they are increasingly secreted from inflamed or damaged tissues, and they may elicit effector responses from innate and adaptive immune cells $(19,102,108)$. Although direct evidence for the role of PP13 as an alarmin has not yet been 
established, these findings suggest that PP13 may function in such way in the placenta in preeclampsia $(19,73)$.

\section{IN VITRO AND IN VIVO FUNCTIONAL STUDIES ON PP13 IN VITRO PARACRINE EFFECTS OF PP13 ON HUMAN IMMUNE CELLS}

PP13 released from the trophoblast into the extracellular space may have various functions similar to other galectins, which may exert their pleiotropic extracellular functions in an autocrine and paracrine manner. Since PP13 is secreted by the trophoblast to the maternal circulation from where it gets into the decidual extracellular matrix (8), PP13 may affect various types of circulating and tissue-resident maternal leukocytes throughout pregnancy. Thus far only a couple of functional experiments were carried out, focusing on the examination of potential extracellular effects of PP13. As several members of the galectin family regulate adaptive immune responses by the induction of apoptosis of activated T lymphocytes (19, 109-111), the apoptosis-inducing effects of PP13 and other chromosome 19 cluster galectins were investigated on activated $\mathrm{T}$ cells freshly isolated from healthy donors (23). Among the studied recombinant galectins, PP13 had the strongest apoptosis-inducing effect (Figures 9A,B), stronger than galectin1 , a protein that has central role in maintaining maternal-fetal immune tolerance in eutherian mammals $(16,19,112)$. A subsequent study also investigated the effect of PP13 on the secretion of cytokines and chemokines from mononuclear cells isolated from peripheral blood of pregnant women (8). The treatment with placenta-purified PP13 slightly increased the secretion of interleukin (IL)-1 $\alpha$ and IL-6 into the culture medium. These in vitro experimental evidences suggest various effects of PP13 on immune cells, which may also be largely dependent on the type, activation and differentiation status of the affected cells, the microvesiclebound or free nature and concentration of PP13, and the redox status of the environment, similarly to other galectins (19).

As with galectins that bind $\mathrm{ABO}$ blood group antigens, the paracrine effects of PP13 may also be affected by this phenomenon (21). In this context, large cohort studies showed that preeclampsia is more frequent among patients with $\mathrm{AB}$ blood group compared to those with non-AB blood groups $(113,114)$. Thus, recently it has been hypothesized that the higher susceptibility to preeclampsia among AB blood group women may be related to the decreased bioavailability and paracrine effects of PP13 on maternal immune cells (21). As a similar phenomenon, the ABO blood group antigens linked to the protein backbone of coagulation factor VIII and von Willebrand factor significantly affect the bioavailability of these blood clotting factors and coagulation (115-118). These findings altogether further underline the important immunoregulatory functions that PP13 may have in early pregnancy and warrant further investigation of the effect of ABO blood group system on PP13 bioavailability and functions. In summary of all of the above, PP13 may have a complex role in the regulation
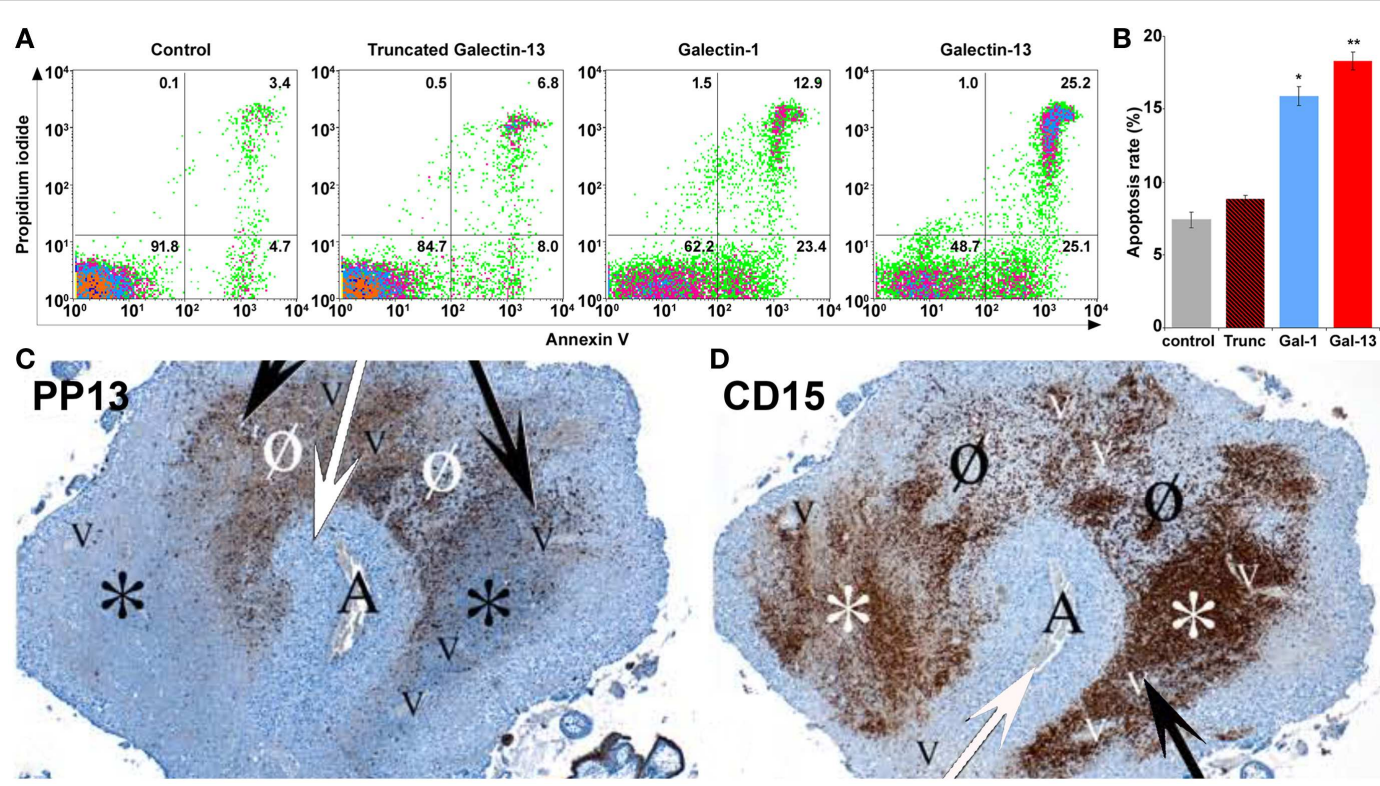

FIGURE 9 | Extracellular PP13 induces apoptosis in vitro and in vivo. (A) The in vitro apoptosis-inducing effect of PP13 on activated CD3+T cells was comparable or stronger than that of galectin-1, whereas truncated PP13 did not have such effect when proteins were applied in $8 \mu \mathrm{M}$ concentration. Numbers in quadrants indicate the percentage of CD3+ T cells. (B) The in vitro apoptosis-inducing effect of PP13 on activated $\mathrm{CD} 3+\mathrm{T}$ cells was stronger than that of galectin-1. Apoptosis rate was calculated as the percentage of Annexin $V$ and propidium iodide double-positive cells. Gal: galectin; Trunc: truncated galectin-13;

${ }^{*} P<0.05$; ${ }^{*} P<0.01$. (C,D) Serial sections of decidua basalis samples in the first trimester. A spiral arteriole (" $\mathrm{A}$ " and white arrows) is surrounded by decidual veins ("V" and black arrows). (C) PP13 immunostainings revealed areas of intense PP13 depositions consistent with early and active zones of necrosis ("ZONE") formation ( $\varnothing$ ), and areas with weak PP13 immunoreactivity consistent with end-stage "ZONEs" (*). (D) CD15 immunostainings revealed neutrophil accumulation showing an inverse pattern with PP13 depositions. The least intense staining was observed in early "ZONEs" (Ø), while the most intense staining in end-stage "ZONEs" (*). Figures and data (A,B) were published in Ref. (23). Figures (C,D) were published in Ref. (8). Kind permission for the reuse and modification of figures was obtained from the National Academy of Sciences of the United States of America (A,B) and SAGE US (C,D). 
of adaptive and innate immune functions at the maternal-fetal interface depending on the changing environment.

THE IN VIVO PARACRINE EFFECTS OF PP13 ON HUMAN IMMUNE CELLS This latter study also described an interesting finding in placental tissue specimens obtained from elective terminations of pregnancies between 6 to 15 weeks of gestation (8). In addition to the PP13 immunopositivity of the syncytiotrophoblast, crystal-like PP13 deposits in the decidual extracellular matrix and phagocytosed PP13 immunopositive material in immune cells were also documented. These deposits were always adjacent to decidual veins but not to arteries, and they were coincident with unique zones of necrotic and apoptotic immune cells (“ZONEs") (Figures 9C,D) (8), a phenomenon that may be consistent with previous findings on zones of decidual necrosis in the first trimester (119). In addition, immunostainings demonstrated the expression of IL$1 \alpha$ and IL- 6 within and around macrophages in these "ZONEs", suggesting the potential pro-inflammatory effect of PP13 (8). The highest number of "ZONEs" appeared to be between 7 to 8 weeks of gestation, and their occurrence declined by the end of the first trimester in parallel with the completion of the spiral artery remodelling and the establishment of the blood circulation to the placenta. This study also revealed that spiral artery transformation by invasive trophoblasts and "ZONEs" were rarely seen in specimens obtained from women with low maternal serum PP13 concentration compared to those with normal PP13 values. In summary, these findings prompted the authors to suggest that syncytiotrophoblast-secreted PP13 reaches the decidual veins, crosses their wall, deposits into the extracellular matrix and forms perivenous crystal-like aggregates near the veins. The lysophospholipase activity associated with PP13 was implicated in this process, but no evidence yet exists to prove it. These PP13 deposits were suggested to serve as "diversion sites" to attract, activate and kill maternal immune cells, drawing these away from sites where the semi-allogeneic fetal trophoblasts invade and remodel maternal spiral arteries. It was also hypothesized that decreased PP13 expression may lead to deficient "ZONE" formation, decreased trophoblast invasion, and the subsequent failure of spiral artery transformation (8). Functional and causal evidence for these in situ observations needs to be provided in the future.

\section{PP13 AND UNIQUE ASPECTS OF DEEP PLACENTATION IN ANTHROPOID PRIMATES}

These in vivo findings are important from an evolutionary point of view since PP13 evolved in Old World monkeys and apes (23), species that have endovascular trophoblast invasion and spiral artery remodelling different from lower primates (120-123). In fact, a growing body of evidence suggests that PP13 may belong to primate-specific molecules (e.g. human leukocyte antigen C, killer-cell immunoglobulin-like receptors), which are involved in the regulation of immune mechanisms related to invasive placentation (124). The findings on PP13 and "ZONE" formation may be mostly related to the pro-apoptotic effect of PP13, similar to the effect of galectin-1 on activated decidual T cells, which is critical in the down-regulation of maternal adaptive immune responses at the maternal-fetal interface in early pregnancy (111). However, the pro-inflammatory action of extracellular PP13 may also fit with early placentation events.

In fact, the early pregnancy decidua is infiltrated by a large number of leukocytes, mainly natural killer (NK) cells (70\%), macrophages (20-25\%), and T cells (10\%) (125-127). These leukocytes, especially decidual natural killer (dNK) cells, macrophages and T regulatory cells, are indispensable for the success of pregnancy since they produce a large variety of chemokines, cytokines, matrix metalloproteinases and angiogenic molecules that regulate maternal-fetal interactions, trophoblast invasion and spiral artery remodelling (127-130). On one hand, these immune cells are involved in the establishment of a delicate immune tolerance between the mother and the fetus, and on the other hand they promote local pro-inflammatory responses that facilitate implantation, trophoblast invasion and placentation events $(126,127)$. These complex immune interactions between the mother and the fetus are conveyed by cell membrane- and vesicle-bound as well as soluble molecules. Among the best studied molecular mechanisms are the effect of progesterone-induced blocking factor (PIBF) on the shift towards Th2 over Th1 cytokine production (131), the anti-inflammatory role of decidual macrophages (132), the immunosuppressive effects of decidual galectin-1 (16), trophoblastic indoleamine 2,3-dyoxignease (IDO), FAS/FAS ligand and galectin-1 $(133,134)$, and the roles of human leukocyte antigen (HLA)-C and HLA-G in protecting fetal cells from NK- and cytotoxic lymphocyte (CTL)-mediated cytolysis $(135,136)$. It is a question for future studies how the actions of PP13 are related to this complex, dynamically changing cellular and molecular network during placentation.

As the result of these complex interactions at the maternal-fetal interface, aggregates of extravillous endovascular trophoblasts plug the openings of uterine spiral arteries; therefore, they inhibit intervillous circulation at the beginning of gestation $(49,120,128)$. This is suggested to be a protective mechanism to keep the developing embryo in a relatively low oxygen environment, minimizing oxidative stress that would lead to developmental defects during organogenesis (137). Of importance, the observed "ZONE" formation peaks when placental circulation is not yet established (8), and the low flow of endometrial gland secretions around the placenta allows the increased transport of PP13 from decidual veins into the decidua. This is also the period when extravillous trophoblast invasion starts into the decidua $(128,137)$. Remarkably, after the start of the placental intervillous circulation at around $8-10$ weeks of gestation $(49,128,137,138)$ PP13 deposits and "ZONE" formation rapidly declines and diminishes by the time intervillous circulation is fully established at about 10-14 weeks of gestation (8). This suggests that PP13 transport is reduced to the decidual extracellular matrix due to the continuously increasing blood flow in spite of the increasing total production of PP13 by the placenta. Importantly, if trophoblastic plug formation is incomplete, placental circulation starts earlier, which leads to the oxidative stress of the placenta, the subsequent development of preeclampsia, and early pregnancy loss in more severe cases (49, $137,138)$. In this context, the earlier start of placental blood flow would theoretically restrict PP13 transport into the decidua and "ZONE" formation, providing another mechanism to hamper normal placentation. 
THE IN VITRO AUTOCRINE EFFECTS OF PP13 ON HUMAN TROPHOBLAST An in vitro study showed the autocrine effect of PP13 measured by its ability to depolarize the membrane of primary trophoblasts isolated from normal and preeclamptic placentas (5). For these experiments, either the patch-clamp technique or a voltage-sensitive fluorescence dye was used, and PP13 was transiently added to the cells. PP13-induced trophoblastic membrane depolarization was increased with extracellular calcium concentrations according to the Nernst equation, and it was blocked in the presence of EGTA, a calcium chelator (5). Furthermore, a two-minute exposure of cells to PP13 resulted in linoleic acid release and subsequent prostacyclin liberation in a calcium-dependent manner. Galectin-1 did not elicit a similar response, indicating the specific effect of PP13. It is interesting that, in contrast, galectin-1 has various effects on trophoblasts including the regulation of hCG and progesterone production (139), proliferation (140), and syncytium formation (141). Based on these results, it would be interesting to further investigate additional autocrine signaling effects of PP13 on the trophoblast at various stages of syncytialization.

\section{THE IN VIVO PARACRINE EFFECTS OF PP13 IN PREGNANT ANIMALS}

Besides in vitro experiments, the in vivo effects of PP13 in an animal model have also been investigated. Initially, non-pregnant rats were exposed to a single bolus of intravenous PP13 injection followed by immediate hypotension and heart rate increase resulting from generalized vasodilatation (142). PP13 was also administered to pregnant rats subcutaneously via osmotic pumps that slowly released PP13 over a period of five days starting from day 15 of pregnancy. In these animals, the hypotension and increased heart rate lasted through the five days of PP13 administration. Furthermore, isolated uterine and mesenteric arteries responded with dilatation to in vitro PP13 treatment as measured by angiography (142). In subsequent studies, the effect of PP13 on uterine vasculature was investigated between days 8 and 15 of pregnancy during a prolonged intraperitoneal exposure through a slow release from osmotic pumps $(35,143)$. Again, PP13 treatment led to a general hypotension that lasted throughout the treatment period, and then blood pressures returned to normal. PP13 treatment affected uterine vasculature with the main effect elicited on uterine veins. These veins had an increased diameter on day 15, while their size returned to normal by day 20. Interestingly, PP13-treated rats delivered slightly larger pups and placentas than saline-treated controls, possibly because of the increased uterine blood flow in these animals (143). These findings may be related to the in vitro prostacyclin liberalization ability of PP13 (5).

PP13 is a primate-specific protein, and thus, certain differences exist between the set of potential "receptors" to which PP13 may bind in rats and primates. Moreover, various differences exist between primate and rodent gestations regarding the length of gestation, uterine anatomy, placentation, litter size, immune regulation, and other aspects. Therefore, the most appropriate context for the in vivo investigations of PP13 effects would be in a pregnant primate model; however, there are ethical limitations for such studies. While there could be major differences between the effects of PP13 in rats compared to humans due to the reasons described above, the effect of PP13 on hypotension and vasodilatation are novel and have not previously been described in regard to any other galectins. In the future, these in vivo effects of PP13 need to be further investigated in humans, presumably on placental bed arteries in hysterectomy specimens and also on placental derived in vitro decidual models in order to evaluate the potential therapeutic use of PP13 to prevent preeclampsia, along with many additional considerations.

\section{FUNCTIONAL CONSIDERATIONS REGARDING THE PP13 CRD}

In vitro experiments on activated $\mathrm{T}$ cells also included their treatment with a truncated, 54-residue PP13 variant that lacks the entire CRD. This truncated protein was expressed from a mutated cDNA that contains the "163C $>$ T" DNA variant frequently observed in cluster galectin pseudogenes in primates (23). Compared to the strong apoptosis inducing effect of PP13, this truncated PP13 had no effect on T cell apoptosis, confirming the crucial role of the CRD in this function (23). In addition, in vivo experiments included the administration of a different truncated PP13 (35), which contains the first 73 amino acids of PP13 similar to the "221delT" native mutant (34). Although this truncated PP13 variant contains 6 out of 8 amino acids from the CRD, its in vivo functional properties were different from PP13 since it caused hypotension in pregnant animals throughout the period of its active release between days 8 to 15 of pregnancy, while it did not increase the birth weight of the pups. Since an increased misfolding of this truncated protein was observed during the isolation from bacteria and the monoclonal anti-PP13 antibodies could not recognize it, it was concluded that its functional properties are different from those of the full length PP13 because of the misfolded structure (35). Further studies are warranted with these truncated PP13 variants to reveal their structural characteristics and effects.

\section{THE EVALUATION OF PP13 IN THE DIAGNOSIS OF PREECLAMPSIA LOW CIRCULATING PP13 mRNA IN MATERNAL BLOOD IN PREECLAMPSIA}

The discovery of fetal DNA and RNA in maternal blood stimulated the experimental assessment of free and cellular PP13 mRNA species in pregnant women's blood in the first half of pregnancy. In accord with the previously discussed placental LGALS13 expression data in preeclampsia, recent studies showed a lower PP13 mRNA content in the maternal blood in the first half of pregnancy in preeclampsia compared to matched controls $(144,145)$. The source of these PP13 mRNA species in maternal blood is only the placenta since no other human tissue expresses PP13 (23), and PP13 mRNA is not detectable in the blood of non-pregnant controls (146). These findings combined with those from placental studies have indicated that pathophysiological changes in PP13 expression appear very early in pregnancy. However, the predictive value of PP13 mRNA species in maternal blood is currently limited, which is most likely associated with varying and low amounts of trophoblastic mRNA reaching the maternal circulation. It is possible that advanced RNA processing techniques and sensitive detection methods like deep sequencing may enable a more robust PP13 mRNA detection in maternal blood for a better performance in preeclampsia prediction in early pregnancy. This aim is currently being supported by the European Union FP7 funded “ASPRE" project. 
FIRST TRIMESTER MATERNAL BLO0D PP13 FOR PREDICTING THE RISK OF THE DEVELOPMENT OF PREECLAMPSIA

The evaluation of PP13 as a protein biomarker for the first trimester prediction of preeclampsia was analyzed with a recent meta-analysis based on studies performed with two immunoassay platforms (147). This meta-analysis explored 68 studies and included 19 into the final analysis, which were published between 2006 and 2013 (21, 37, 148-164). The analysis pooled the results from only singleton pregnancies of low or high risk women or all-comer cohorts, which were included in prospective or nested case-control studies, or fully prospective studies. A total of 16,153 pregnant women were tested for PP13 in the first trimester (between gestational weeks 6 and 14), among whom 1,197 developed subsequently preeclampsia. Out of these cases there were $19 \%$ who developed early-onset preeclampsia ( $<34$ weeks) and $45 \%$ who developed preterm preeclampsia ( $<37$ weeks).

Ten studies used the ELISA platform developed in Israel (21, 37, 148-152, 154, 160, 164), one study used the ELISA platform recently developed in China (161), and the remaining studies used the DELFIA platform. In all studies, PP13 blood concentrations were converted into gestational week-specific multiples of the medians (MoMs) (165), and then were further adjusted to maternal weight in two studies $(156,164)$ or to body mass index (BMI). In 10 studies, the PP13 MoMs were further adjusted to smoking, ethnicity, maternal age and parity. Interestingly, one study also adjusted PP13 MoMs to conception by in vitro fertilization (IVF) (164), and another study, which yielded the highest sensitivity and specificity, further adjusted PP13 MoMs to ABO blood groups (21).

All studies in the meta-analysis utilized algorithms that calculated the receiver operating characteristics (ROC) curves to detect the sensitivity and specificity, and logistic regression analysis to predict the risk of preeclampsia (147). When all cases of preeclampsia were included in the meta-analysis, the mean detection rate (DR) for predicting preeclampsia was $47 \%$ ( $95 \%$ confidence interval, CI: $43-65)$ at a $10 \%$ false positive rate (FPR). The DR of PP13 for preterm preeclampsia was higher, $66 \%$ (95\% CI: $48-78$ ), and for early-onset preeclampsia it was $83 \%$ (95\% CI: 25-100). The assessment of likelihood ratios (LRs) for all cases of preeclampsia revealed a positive LR [sensitivity/(1-specificity)] of 5.82, a negative LR [(1-sensitivity)/specificity] of 0.46 and an overall LR (positive LR/negative LR) of 26.35, while the positive, negative and overall LRs for preterm preeclampsia were 6.94, 0.34, and 40.07 , respectively.

The median PP13 MoMs and 95\% CIs varied considerably between the different studies. Comparison of the DELFIA and ELISA studies showed that the DR for all preeclampsia cases at 10\% FPR was $78.75 \%$ (95\% CI: 68.44-88.22) with the ELISA platform and $40.29 \%$ (95\% CI: 0-61.19) with the DELFIA platform. The positive, negative and overall LRs were 8.25, 0.19 and 53.26 with the ELISA platform and 5.03, 0.55 and 13.29 with the DELFIA platform, respectively. It has also been demonstrated that the ELISA assay of the same samples provides better segregation of PP13 values between preeclampsia cases and controls than the DELFIA assay (166). Among the eight DELFIA assay based studies, good preeclampsia prediction was achieved in two $(156,157)$, no prediction was achieved in three $(155,159,162)$, while varying, moderate prediction was achieved in the rest of the studies. The DELFIA platform differs from the ELISA platform since it includes the capture and detection antibodies in an inverted order, and it utilizes Europium amplification compared to the use of the biotin-extravidin-horse radish peroxidase amplification in the ELISA. These differences may account for some of the differences detected in assay performances (166). However, recent results may suggest that batch differences in the Fab domain of one of the antibodies also play a role in this phenomenon, which is now under examination with the new generation of PP13 kits developed by the "ASPRE" project.

In view of the differential binding of PP13 to cell surfaces containing $\mathrm{ABO}$ blood group antigens, and its varying bioavailability in maternal blood depending on the $\mathrm{ABO}$ blood type, the adjustment of PP13 MoMs to ABO blood groups further improved their predictive value for preeclampsia as well as for IUGR and the two combined (21). For example, Caucasian and Hispanic women with blood group $\mathrm{AB}$ had the lowest, and those with blood group $\mathrm{B}$ had the highest first trimester maternal serum PP13 MoMs, while individuals with blood group $\mathrm{A}$ or O had intermediate MoMs (21). After adjustment of PP13 MoMs to ABO blood groups, the overall LR for predicting IUGR increased from 2.2 to 5.32 , the overall LR for predicting preeclampsia increased from 6.9 to 18.1, and the overall LR for predicting preeclampsia associated with IUGR increased from 5.6 to 27.9.

Earlier studies have shown increased accuracy for the prediction of severe cases of preeclampsia over the mild ones $(152,154,157)$. Based on these findings, the large differences in prediction accuracy demonstrated in the meta-analysis can probably be attributed to the differences in the severity of the included cases. This phenomenon as well as the observation on the reduced first trimester PP13 MoMs after IVF (164) are under further examination by the "ASPRE" project, which targets the longitudinal, multi-center examination of 33,000 maternal blood specimens.

\section{PERFORMANCE OF FIRST TRIMESTER PP13 AS PART OF A MULTIPLE MARKER PANEL}

A growing body of evidence suggests that the prediction of preeclampsia can be improved using multi-parametric approaches, combining data derived from multiple biomarkers $(153,165)$. Initially, PP13 was evaluated as a single marker with MoMs adjusted to various pregnancy features as detailed above. It was then evaluated over a background risk calculated according to preeclampsia in a previous pregnancy, medical history of gestational diabetes, kidney and cardiovascular diseases, maternal age, ethnicity, BMI and conception by assisted reproduction techniques. This analysis showed that the sensitivity of PP13 for predicting all cases of preeclampsia increased from 52 to $59 \%$ at $10 \%$ FPR after combining with background risk factors (167). Subsequently, PP13 and background risk factors were also combined with the mean arterial pressure (MAP), which further increased the detection rate to $93 \%$ for all cases of preeclampsia at $10 \%$ FPR (167). Combining PP13 with placental growth factor (PlGF) (156) or with additional biochemical markers [i.e. pregnancy associated plasma protein A (PAPP-A), PlGF and ADAM metallopeptidase domain 12 (ADAM12)] were also accompanied by an increased 
DR for preeclampsia in spite of the varying predictive values of the individual biomarkers (165). In seven studies, the risk prediction was based on combining PP13 and uterine artery Doppler pulsatility index (PI), which also showed increased prediction accuracy $(148,150,154,157,165,168,169)$. Comprehensive risk algorithms were further developed based on a combined multi-marker analysis that took into consideration the background risk (as detailed above), MAP, Doppler PI, and a panel of serum biomarkers. This approach yielded much higher predictive value and accuracy than individual markers (157), especially for early-onset ( $<34$ weeks) and preterm ( $<37$ weeks) preeclampsia. This is consistent with the results of several other studies that used combined biomarker panels and various types of risk prediction algorithms to obtain better risk prediction (170-172). It was therefore concluded that the introduction of a broad biomarker panel for the evaluation of preeclampsia and other maternal and fetal pregnancy disorders could present a change in deploying antenatal care as formulated by the inverted pyramid model of perinatal evaluation in pregnancy (173). In agreement with these, the combination of PP13, Doppler PI, MAP (or maternal artery stiffness) increased the DR of preeclampsia to $93 \%$ for early-onset preeclampsia and to $86 \%$ for all preeclampsia cases at 10\% FPR (174). This preeclampsia prediction accuracy satisfies the World Health Organization (WHO) requirements for the clinical introduction of a disorder predicting procedure in terms of clinical usefulness in disease management and disorder prevention $(175,176)$.

\section{LONGITUDINAL ASSESSMENT OF PP13 IN MATERNAL BLOOD}

A repeated measure of a marker level was identified as a better method to get a more accurate prediction of the risk to develop pregnancy disorders, initially for Down syndrome (177) and also for preeclampsia $(178,179)$, or for IUGR and preeclampsia combined (180). A large study on PP13, which utilized repeated measures in the first, second and third trimesters, provided increased prediction accuracy compared to the first trimester test alone, either when a contingent or a combined model was used (151). This was further confirmed in a smaller study using repeated measures of PP13 every $2-4$ weeks $(37,147)$.

The significance of the repeated measure of PP13 is also high since gestational age-related changes in maternal blood PP13 concentrations are very different between normal pregnancy and those with preeclampsia. While in patients who develop preeclampsia PP13 concentrations are lower in the first trimester than in normal pregnant women, the use of repeated measures of PP13 in longitudinal or cross-sectional studies showed that PP13 concentrations sharply increase in preeclampsia patients between the first and third trimesters compared to the moderate change that can be observed in women with normal pregnancy. The most prominent increase is seen when preeclampsia enters into the clinico-pathological stage. For example, between the first and third trimesters, maternal PP13 MoMs were detected to increase by $\sim 1.5$ to 3 -fold in normal pregnancy compared to the 3.5 to 7.7 fold increase in preeclampsia, and occasionally even more $(21,36$, $37,98,151,181)$. Interestingly, the slope of increase was different among individuals, and it seemed to be related to patient characteristics like obesity, ethnicity, maternal age, parity, and particularly the severity of the disease.
Of importance, when taking into account the effect of $\mathrm{ABO}$ blood groups on the longitudinal changes in PP13 across the three trimesters, the regression slope of PP13 concentrations and MoMs were steeper in blood group B than in blood groups A and $\mathrm{O}$, but not in blood group $\mathrm{AB}$. The characteristic changes during gestation in serum PP13 concentrations in women with different $\mathrm{ABO}$ blood groups inversely mirrored the relative binding of PP13 to various $\mathrm{ABO}$ blood group erythrocytes, suggesting a dynamic change in PP13 sequestration on erythrocyte surfaces depending on gestational age and actual PP13 concentrations (Figure 3C) (21).

As described before, there is an increased shedding of PP13rich syncytiotrophoblastic microvesicles from placental villi when women enter into the clinico-pathological stage of preterm preeclampsia $(36,37)$. Importantly, it was proposed that these microvesicles release their PP13 content, leading to the increased maternal blood PP13 concentrations in these cases $(36,37,73)$. Since the extent of microvesicle shedding is related to the extent of placental ischemic stress and it is significantly more pronounced in severe cases of preeclampsia, particularly with preterm than with term onset (182), the longitudinal slope of changes in PP13 could be used as an additional parameter to predict case severity $(36,151)$. This phenomenon explains why so much difference was found in early-onset or preterm preeclampsia in PP13 compared to gestational-age matched controls in the third trimester.

\section{META-ANALYSIS FOR THE PREDICTION OF THE RISK FOR PREECLAMPSIA WITH THIRD TRIMESTER PP13 METHODS AND INCLUDED STUDIES}

Because of the increased PP13 concentrations in preeclampsia in the third trimester, it was hypothesized that PP13 testing can be further utilized for the prediction and diagnosis of preeclampsia during this period. To address this question, we have conducted a meta-analysis on third trimester datasets and found studies that utilized the PP13 ELISA but not DELFIA platform. The PP13 ELISA utilizes a pair of anti-PP13 mouse monoclonal antibodies (27-2-3 and 215-28-3 MAbs) that were selected based on their high $\left(10^{-9} \mathrm{M}\right)$ affinity to native and recombinant PP13 $(5,71)$. As a result, the detection limit of the ELISA was 3-8 pg/ml, the linear detection range was between $12.5-400 \mathrm{pg} / \mathrm{ml}$, and the kit-to-kit, operator-to-operator and batch-to-batch variations were between 3-12\% (5).

From the 71 studies published on PP13, the current metaanalysis identified eight clinical studies published between August 2008 and March 2014 that contained third trimester maternal blood PP13 data. These had an international scope involving Israel $(71,98,151)$, Hungary $(36)$, Austria $(37,181)$ and the USA (21). These studies were either performed as part of longitudinal clinical trials or cross-sectional studies that focused on the ELISA-based evaluation of PP13 between 26 and 40 weeks of gestation. In all studies, the ROC curves were based on PP13 adjusted to gestational week specific MoMs, which were further adjusted to BMI, smoking, ethnicity, maternal age as well as parity. In one study, PP13 values were further adjusted to the ABO blood groups (21). In a very recent study the adjustment was further made to conception by IVF (167). 


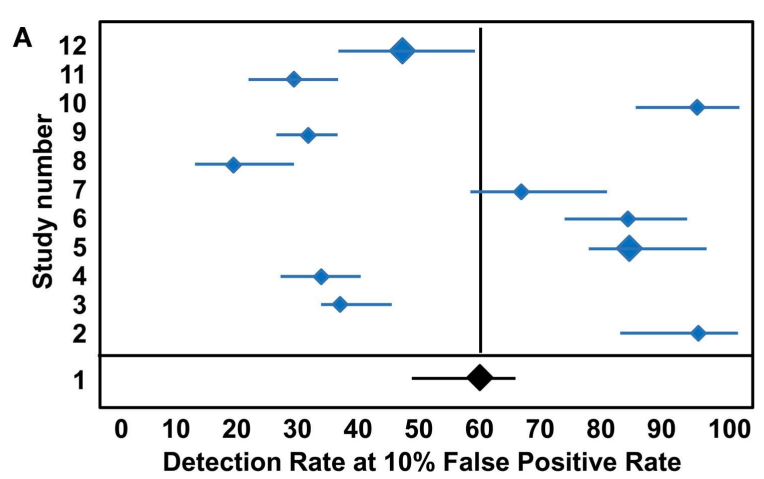

B

\begin{tabular}{|c|c|c|c|c|c|c|c|c|c|c|}
\hline $\begin{array}{c}\text { Study } \\
\text { number }\end{array}$ & Reference & $\begin{array}{c}\text { Publication } \\
\text { year }\end{array}$ & $\begin{array}{c}\text { Study design } \\
12\end{array}$ & Gopulation & $\begin{array}{c}\text { GA at } \\
\text { test }\end{array}$ & $\begin{array}{c}\text { PE } \\
\text { patients }\end{array}$ & $\begin{array}{c}\text { All } \\
\text { patients }\end{array}$ & $\begin{array}{c}\text { Weight in } \\
\text { analysis }\end{array}$ & $\begin{array}{c}\text { DR } \\
(95 \% \text { CI) }\end{array}$ & Overall LR \\
\hline 11 & Huppertz et al. & 2008 & $\begin{array}{c}\text { Prospective } \\
\text { cohort }\end{array}$ & All-comers & $24-28$ & 20 & 1,198 & 0.435 & $48.0(38-57)$ & 8.31 \\
\hline 10 & Huppertz et al. & 2008 & $\begin{array}{c}\text { Prospective } \\
\text { cohort }\end{array}$ & All-comers & $31-35$ & 4 & 67 & 0.024 & $30.8(24-36)$ & 4.02 \\
\hline 9 & Than et al. & 2008 & Case-control & All-comers & $28-32$ & 11 & 57 & 0.021 & $33.0(28-36)$ & 4.43 \\
\hline 8 & Than et al. & 2008 & Case-control & All-comers & $33-38$ & 9 & 57 & 0.021 & $21.0(15-29)$ & 2.39 \\
\hline 7 & Grimpel et al. & 2011 & Case-control & All-comers & $28-32$ & 11 & 78 & 0.028 & $67.0(59-79)$ & 18.27 \\
\hline 6 & Sammar et al. & 2011 & Case-control & All-comers & $30-34$ & 12 & 75 & 0.027 & $83.7(74-92)$ & 46.21 \\
\hline 5 & Than et al. & 2011 & $\begin{array}{c}\text { Prospective } \\
\text { cohort }\end{array}$ & All-comers & $24-28$ & 15 & 815 & 0.296 & $84.0(78-95)$ & 47.25 \\
\hline 4 & Huppertz et al. & 2013 & $\begin{array}{c}\text { Prospective } \\
\text { cohort }\end{array}$ & All-comers & $28-31$ & 30 & 154 & 0.056 & $35.0(28-40)$ & 4.85 \\
\hline 3 & Huppertz et al. & 2013 & $\begin{array}{c}\text { Prospective } \\
\text { cohort }\end{array}$ & All-comers & $32-36$ & 34 & 150 & 0.054 & $38.0(35-45)$ & 5.52 \\
\hline 2 & Meiri et al. & 2014 & $\begin{array}{c}\text { Prospective } \\
\text { cohort }\end{array}$ & All-comers & $24-28$ & 3 & 38 & 0.014 & $95.0(83-100)$ & 171.00 \\
\hline 1 & Total & & Meta-analysis & & $24-40$ & 193 & 2,754 & 1.00 & $59.4(49.7-64.5)$ & 26.24 \\
\hline
\end{tabular}

FIGURE 10 | Meta-analysis of PP13 in predicting preeclampsia in the third trimester. (A) A Forest plot analysis was performed including 11 studies based on unaffected and all preeclampsia cases. The detection rate (DR) at $10 \%$ False Positive Rate (FPR) of all cases of preeclampsia is shown in case-control and prospective cohort studies using all-comers. The DR was extracted from Receiver Operation Characteristics (ROC) curves based on the adjusted multiple of the medians (MoMs) of PP13. The final analysis took into consideration the total study size and the size of the preeclampsia group. Number 1 on the study list reflects the results of the meta-analysis depicted with a dark filled diamond compared to individual studies depicted with blue diamonds. The relative weight of a certain study in the analysis is reflected by the relative size of the diamonds. (B) The table lists all studies used to perform the Forest plot for the meta-analysis. Weight represents the relative impact of the study in the meta-analysis. DR for 10\% FPR is shown along with the $95 \%$ confidence interval $(95 \% \mathrm{Cl})$. The Likelihood ratio (LR) was calculated for positive LR [sensitivity/(1-specificity)], negative LR [(1-sensitivity)/specificity] and overall LR (positive LR/negative LR). For the meta-analysis, the values were adjusted to the relative weight of each study in the meta-analysis. The numbers on the left side of the table correspond to the graph numbers in (A). PE, preeclampsia; GA, gestational age in weeks.
The meta-analysis was performed by a Forest plot method (183). There were three occasions in which the determination of PP13 in maternal blood was extracted from studies performed in separate time points, which were included as separate studies (36, 181, 184). Accordingly, the dataset for the analysis was based on 11 cohorts. The DR at 10\% FPR was extracted from the published ROC curves or by communicating with the authors and obtaining complementary data. The $95 \%$ CI of the DR was extracted or calculated from ROC curves of the published study or by using the web-calculator ${ }^{2}$. The analysis pooled clinical results from all singleton pregnancy studies, irrespective whether these were prospective cohort studies or case-control studies that enrolled low- or high-risk patients or all-comers. The pooled dataset included all

${ }^{2}$ http://www.causascientia.org/math_stat/ProportionCI.html preeclampsia cases and then a sub-analysis was performed for preterm and early-onset preeclampsia cases. Preeclampsia associated with IUGR and/or HELLP syndrome was compared to all preeclampsia cases, but there were too few cases with these additional complications to enable a true meta-analysis.

Regarding the detection level, the meta-analysis has also evaluated the overall LR of developing preeclampsia by dividing the positive LR with the negative LR as described earlier. The overall LR calculation took into consideration the relative weight of each of the cohorts in terms of study size and the number of women with preeclampsia.

\section{RESULTS OF THE META-ANALYSIS}

In total, 2,750 third trimester pregnant women were tested. 193 women subsequently developed preeclampsia out of whom $30.7 \%$ had preterm preeclampsia and 7.6\% had early-onset preeclampsia. 
All but one study enrolled all-comers, and only one study enrolled high-risk patients. In this latter study the correlation between having prior risk of preeclampsia based on major risk factors and a high level of PP13 in the third trimester was low $(R=0.13)$, indicating that the two are independent evaluators (167).

In all studies, maternal blood PP13 MoMs were higher in women who subsequently developed preeclampsia compared to unaffected women although the variation between individual data-points within a study or between studies was large. Therefore, the sensitivity of using PP13 as a biomarker for predicting the risk of the subsequent development of preeclampsia had a broad range (14-100\%). The mean DR at $10 \%$ FPR for all preeclampsia cases was 59.4\% (95\% CI: 49.7-64.5) (Figures 10A,B). The DR of PP13 for preterm preeclampsia (which included all early-onset preeclampsia cases) was 71.7\% (95\% CI: 60.3-75.3) (Figures 11A,B). Since there were few studies with data from patients with early-onset preeclampsia, this separate analysis had insufficient power for statistical analysis.

The time of detection ranged between $28-32$ to $36-40$ weeks, and the evaluation of the DR per gestational week yielded a regression line of $\mathrm{Y}=1.3986 \mathrm{X}+100.58$, where $\mathrm{X}$ was the gestational week and the regression coefficient $(R)$ was 0.2 . These results have indicated that the variations are indeed independent of the gestational week at testing. When evaluated according to the correlation with MAP or urine protein, the DR appeared to be related to the severity of the cases in a given study, with regression coefficient values of 0.61 and 0.73 , respectively. This means that the higher the hypertension and proteinuria, the higher the third trimester PP13 MoMs in maternal blood, and the better the prediction. A combined algorithm of PP13, MAP and proteinuria, which was available for nine out of the 11 studies, yielded a 95\% DR for preterm preeclampsia and $85 \%$ for all preeclampsia at $5 \%$ FPR, showing the value of combining all parameters (data not shown). In conclusion, the meta-analysis indicates that higher third trimester maternal blood PP13 among women who will subsequently develop preeclampsia reaches the clinical diagnostic level.

The positive LR for all cases of preeclampsia in the metaanalysis was 5.94 and the negative LR was 0.45 , providing an overall LR of 26.24 (Figure 10B). The positive LR for preterm preeclampsia in the meta-analysis was 7.17 and the negative LR was 0.31 , providing an overall LR of 37.99 (Figure 11B). These LRs are lower compared to the overall LRs of first trimester PP13, but these can still be considered respected LRs by the criteria of the WHO (176).

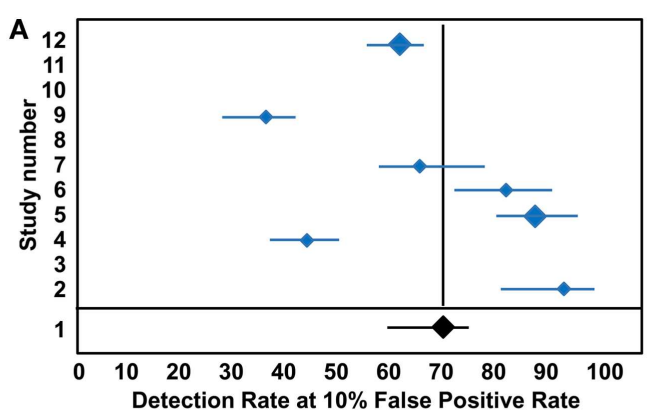

B
\begin{tabular}{|c|c|c|c|c|c|c|c|c|c|c|}
$\begin{array}{c}\text { Study } \\
\text { number }\end{array}$ & Reference & $\begin{array}{c}\text { Publication } \\
\text { year }\end{array}$ & Study design & Population & $\begin{array}{c}\text { GA at } \\
\text { test }\end{array}$ & $\begin{array}{c}\text { PE } \\
\text { patients }\end{array}$ & $\begin{array}{c}\text { All } \\
\text { patients }\end{array}$ & $\begin{array}{c}\text { Weight in } \\
\text { analysis }\end{array}$ & $\begin{array}{c}\text { DR } \\
(95 \% \text { CI) }\end{array}$ & Overall LR \\
\hline 12 & Gonen et el. & 2008 & $\begin{array}{c}\text { Prospective } \\
\text { cohort }\end{array}$ & All-comers & $24-28$ & 5 & 1183 & 0.503 & $63.1(57-67)$ & 15.32 \\
\hline 9 & Than et al. & 2008 & Case-control & All-comers & $28-32$ & 8 & 54 & 0.023 & $37.0(29-42)$ & 5.29 \\
\hline 7 & Grimpel et al. & 2011 & Case-control & All-comers & $28-32$ & 11 & 78 & 0.033 & $67.0(59-79)$ & 18.27 \\
\hline 6 & Sammar et al. & 2011 & Case-control & All-comers & $30-34$ & 12 & 75 & 0.032 & $83.7(74-92)$ & 46.21 \\
\hline 5 & Than et al. & 2011 & $\begin{array}{c}\text { Prospective } \\
\text { cohort }\end{array}$ & All-comers & $24-28$ & 5 & 805 & 0.343 & $89.0(82-97)$ & 72.82 \\
\hline 4 & Huppertz et al. & 2013 & $\begin{array}{c}\text { Prospective } \\
\text { cohort }\end{array}$ & All-comers & $28-31$ & 14 & 117 & 0.050 & $45.0(38-50)$ & 7.36 \\
\hline 2 & Meiri et al. & 2014 & $\begin{array}{c}\text { Prospective } \\
\text { cohort }\end{array}$ & All-comers & $24-28$ & 3 & 38 & 0.016 & $95.0(83-100)$ & 171.00 \\
\hline 1 & Total & & Meta-analysis & & $24-32$ & 58 & 2,350 & 1.00 & $71.7(60.3-75.3)$ & 37.99 \\
\hline
\end{tabular}

FIGURE 11 | Meta-analysis of PP13 in predicting preterm preeclampsia in the third trimester. (A) Forest plot analysis was performed including seven studies based on unaffected and preterm preeclampsia cases. The detection rate (DR) at 10\% False Positive Rate (FPR) of cases of preterm preeclampsia is shown in case-control and prospective cohort studies using all-comers. The DR was extracted from Receiver Operation Characteristics (ROC) curves based on the adjusted multiple of the medians (MoMs) of PP13. The final analysis took into consideration the total study size and the size of the preeclampsia group. Number 1 on the study list reflects the results of the meta-analysis depicted with a dark filled diamond compared to individual studies depicted with blue diamonds. The relative weight of a certain study in the analysis is reflected by the relative size of the diamonds. (B) The table lists studies used to perform the Forest plot for the meta-analysis of cases of preterm preeclampsia $<37$ weeks), including early onset preeclampsia ( $<34$ weeks). Weight represents the relative impact of the study in the meta-analysis. DR for $10 \%$ FPR is shown along with the 95\% confidence interval (95\% Cl). The Likelihood ratio (LR) was calculated for positive LR [sensitivity/(1-specificity)], negative LR [(1-sensitivity)/ specificity] and overall LR (positive LR/negative LR). For the meta-analysis, the values were adjusted to the relative weight of each study in the meta-analysis. The numbers on the left side correspond to the graph numbers in (A). PE, preeclampsia; GA, gestational age in weeks. 
Reduced blood concentrations of PIGF in the third trimester have been suggested for predicting the symptoms of preeclampsia within 14 days of the test. This fast and quantitative TRIAGE test, measuring the decreased PlGF concentrations in maternal blood, also predicts the anticipated disease severity $(185,186)$. Of interest, the combination of anti-angiogenic factors and PlGF (or their ratio) increase the prediction rate of severe late-onset preeclampsia in the third trimester (179). Combining low PIGF with high PP13 maternal blood concentrations may generate an even better test. Thus, it is essential to investigate the PP13/PIGF ratio as a better diagnostic tool for preeclampsia in the third trimester. This will be further explored by the "ASPRE" project, in which at least 1,500 high-risk patients out of the 33,000 enrolled pregnant women will be tested longitudinally in the first, second and third trimesters of pregnancy.

\section{SUMMARY AND CONCLUSIONS}

Galectins are glycan-binding proteins that regulate innate and adaptive immune responses, and some galectins confer maternalfetal immune tolerance in eutherian mammals. A chromosome
19 cluster of galectin genes has emerged in anthropoid primates, species with deep placentation and long gestation, in which this galectin network may confer additional immunoregulatory functions to enable deep placentation. These cluster galectins, including PP13, have a conserved structure, CRD and sugar-binding preference resembling other mammalian galectins. PP13 is solely expressed by the human placenta, predominantly by the syncytiotrophoblast, from where it is released into the maternal blood. PP13 expression and release from the individual placental villi is highest in the first trimester when maternal immune cell infiltration into the decidua is at its peak (Figure 12) to promote successful placentation including embryo implantation, trophoblast invasion, repair of the uterine epithelium and removal of cellular debris. Of interest, PP13 released from the villi is deposited around uterine veins and contributes to the formation of "ZONEs" of apoptotic and necrotic immune cells, which peak parallel with the start of spiral artery remodelling in the first trimester. Because PP13 is capable of inducing the apoptosis of activated $\mathrm{T}$ cells and the cytokine production of macrophages, it was postulated that these PP13 deposits in the decidual extracellular matrix may

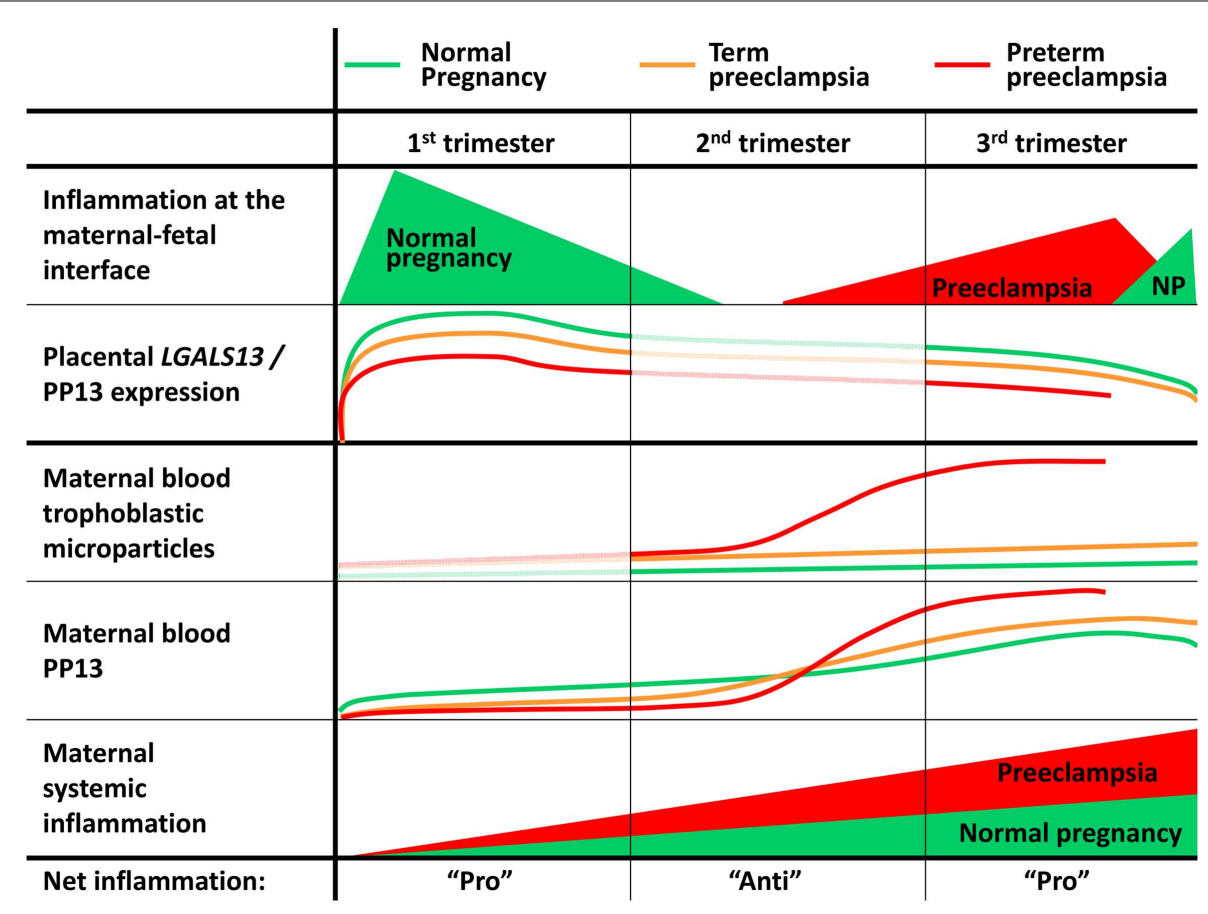

FIGURE 12 | PP13 expression is related to inflammatory changes at the maternal-fetal interface and in maternal circulation. This summary figure consolidates the results of numerous studies related to various facets of PP13 in normal pregnancies and in preeclampsia. The placental expression of LGALS13 and PP13 is strong in the first trimester, and the secreted protein can be detected in maternal blood from gestational weeks 5 to 6 in normal pregnancies. From the decidual veins PP13 gets into the decidua, where it is deposited extracellularly or phagocytosed, coincident with maternal immune cell infiltration and the formation of the "Zones of Necrosis" (ZONEs) adjacent to the decidual veins. Although maternal serum PP13 concentrations do not change, the relative placental expression and decidual deposition of PP13 declines until the end of the first trimester in parallel with the decrease in the number of ZONEs. In the second and third trimesters, maternal serum PP13 concentrations rise due to the growing number of villi and trophoblast volume in the placenta, paralleling the escalation in maternal systemic inflammation. In preeclampsia, especially in early-onset cases, there are lower placental expression and maternal serum concentrations of PP13 in the first trimester, coincident with impaired trophoblast invasion and spiral artery remodelling. Starting from the second trimester, ischemic placental stress and pro-inflammatory changes at the maternal-fetal interface are also reflected by the increased shedding of aponecrotic microvesicles, which carry a considerable amount of PP13, elevating maternal blood PP13 concentrations. PP13 expression in the first trimester is associated with inflammation at the maternal-fetal interface. Similarly, maternal blood PP13 concentrations in the second and third trimesters parallel maternal systemic inflammation. As a consequence, PP13 has a good diagnostic value for the prediction and diagnosis of preeclampsia in the first and third trimesters. NP: normal pregnancy. 
attract maternal immune cells away from the sites of maternal spiral artery formation to the decidual veins, and may promote a tolerogenic environment that facilitates trophoblast invasion and placentation. How important the roles of PP13 are during early placentation may be well reflected by observations showing decreased placental expression and maternal serum concentrations of PP13 in the first trimester in preeclampsia (Figure 12), a syndrome originating from severely impaired trophoblast invasion and placentation. Moreover, mutations in the promoter and in the exons of $L G A L S 13$ presumably leading to altered, misfolded or non-functional protein expression are associated with a higher frequency of preeclampsia and also other obstetrical syndromes which involve immune dysregulation.

PP13 maternal blood concentrations steeply increase in preeclampsia compared to normal pregnancy starting in the second trimester, with the steepness correlated to disease severity. This phenomenon is closely related to the ischemic placental stress and the consequent increase in trophoblastic shedding of PP13 immunopositive microvesicles (Figure 12). Because of the proinflammatory nature of these aponecrotic trophoblast microvesicles and other "toxins" released from the placenta, preeclampsia, especially its early-onset subform, is characterized by an exaggerated maternal systemic inflammation and generalized endothelial dysfunction, leading to kidney damage, proteinuria and hypertension. It is interesting that reduced placental PP13 expression in preeclampsia correlates with altered immune-interactions at the maternal-fetal interface. Similarly, maternal blood PP13 concentrations in the second and third trimesters are elevated in relation to the increased placental stress and maternal systemic inflammation (Figure 12). These phenomena have already been utilized for developing a PP13 blood test for predicting preeclampsia, and indirectly for impaired placentation, in the first trimester. The analysis provided here shows that this test may be further used for preeclampsia diagnosis in the third trimester.

Functional studies have just started to assess the in vitro and in vivo effects of PP13 during pregnancy, showing various functions that PP13 may have at the maternal-fetal interface. In vitro studies need to take into account the pleiotropic actions of PP13, which may depend on the activation and differentiation status of the affected cells, the way PP13 is released from the placenta (e.g. free or extracellular vesicle-bound), the redox status of the environment, and the interaction of PP13 with various small molecules. In vivo studies, while starting in rodents, may eventually need to be extended to other models, optimally to primates. Nevertheless, the results of the first studies support the importance of PP13 in the regulation of blood pressure and vascular remodelling at the maternal-fetal interface.

\section{ACKNOWLEDGMENTS}

The preparation and publication of this manuscript was sponsored, in part, by the European Union FP7 "ASPRE" project (\#601852 to Hamutal Meiri and Sveinbjorn Gizurarson), the Hungarian OTKA-PD grant (\#104398 to Andrea Balogh), and the Hungarian Academy of Sciences Momentum grant (\#LP20147/2014 to Nándor Gábor Than). Many of the published studies conducted between 2006 and 2010 were funded by the European Union FP6 “Pregenesys” project (\#037244 to Hamutal Meiri and
Nándor Gábor Than) and by the Perinatology Research Branch, Division of Intramural Research, Eunice Kennedy Shriver National Institute of Child Health and Human Development, National Institutes of Health, Department of Health and Human Services (NICHD/NIH/DHHS). The Foundation of Helgu Jónsdóttur and Sigurliða Kristjánsson (Iceland) sponsored the animal studies with rats (to Sveinbjorn Gizurarson). PP13, anti-PP13 monoclonal antibodies and ELISA kits were produced by Hy-Laboratories for the animal studies along with some of the clinical studies about PP13 which were included in either the first or the third trimester meta-analysis. The authors thank Dr. Harvey J. Kliman (Yale University, New Haven, CT, USA) for helpful discussions, Dr. Ruth Cohen and Alla Tractenhaertz for providing unpublished information on the new generation of PP13 kits and their help with this publication, and for Sara Tipton (Wayne State University) for her critical reading of our manuscript.

\section{REFERENCES}

1. Than NG. Obituary: Hans Bohn, 1928-2014. Placenta (2014). doi:10.1016/j. placenta.2014.04.016

2. Than GN, Bohn H, Szabo DG. Advances in Pregnancy-Related Protein Research. Boca Raton, FL: CRC Press (1993).

3. Bohn H, Kraus W, Winckler W. Purification and characterization of two new soluble placental tissue proteins (PP13 and PP17). Oncodev Biol Med (1983) 4:343-50.

4. Than GN, Szabo D, Gocze P, Arany A, Bognar Z. Lepenyi feherjek (PP5, PP10, PP12, PP13, PP17) szerum- es magzatvizertekei egeszseges terhessegekben. Magy Noorv L (1986) 49:11-5.

5. Burger O, Pick E, Zwickel J, Klayman M, Meiri H, Slotky R, et al. Placental protein 13 (PP-13): effects on cultured trophoblasts, and its detection in human body fluids in normal and pathological pregnancies. Placenta (2004) 25:608-22. doi:10.1016/j.placenta.2003.12.009

6. Than NG, Sumegi B, Than GN, Berente Z, Bohn H. Isolation and sequence analysis of a cDNA encoding human placental tissue protein 13 (PP13), a new lysophospholipase, homologue of human eosinophil Charcot-Leyden crystal protein. Placenta (1999) 20:703-10. doi:10.1053/plac.1999.0436

7. Ackerman SJ, Corrette SE, Rosenberg HF, Bennett JC, Mastrianni DM, Nicholson-Weller A, et al. Molecular cloning and characterization of human eosinophil Charcot-Leyden crystal protein (lysophospholipase). Similarities to IgE binding proteins and the S-type animal lectin superfamily. J Immunol (1993) 150:456-68.

8. Kliman HJ, Sammar M, Grimpel YI, Lynch SK, Milano KM, Pick E, et al. Placental protein 13 and decidual zones of necrosis: an immunologic diversion that may be linked to preeclampsia. Reprod Sci (2012) 19:16-30. doi:10.1177/ 1933719111424445

9. Than NG, Pick E, Bellyei S, Szigeti A, Burger O, Berente Z, et al. Functional analyses of placental protein 13/galectin-13. Eur J Biochem (2004) 271:1065-78. doi:10.1111/j.1432-1033.2004.04004.x

10. Ackerman SJ, Liu L, Kwatia MA, Savage MP, Leonidas DD, Swaminathan GJ, et al. Charcot-Leyden crystal protein (galectin-10) is not a dual function galectin with lysophospholipase activity but binds a lysophospholipase inhibitor in a novel structural fashion. J Biol Chem (2002) 277:14859-68. doi:10.1074/jbc.M200221200

11. Visegrady B, Than NG, Kilar F, Sumegi B, Than GN, Bohn H. Homology modelling and molecular dynamics studies of human placental tissue protein 13 (galectin-13). Protein Eng (2001) 14:875-80. doi:10.1093/protein/14.11.875

12. Gabius HJ, Andre S, Kaltner H, Siebert HC. The sugar code: functional lectinomics. Biochim Biophys Acta (2002) 1572:165-77. doi:10.1016/S0304-4165(02) 00306-9

13. Barondes SH, Gitt MA, Leffler H, Cooper DN. Multiple soluble vertebrate galactoside-binding lectins. Biochimie (1988) 70:1627-32. doi:10.1016/03009084(88)90298-2

14. Hirabayashi J, Kasai K. The family of metazoan metal-independent betagalactoside-binding lectins: structure, function and molecular evolution. Glycobiology (1993) 3:297-304. doi:10.1093/glycob/3.4.297 
15. Cooper DN. Galectinomics: finding themes in complexity. Biochim Biophys Acta (2002) 1572:209-31. doi:10.1016/S0304-4165(02)00310-0

16. Blois SM, Ilarregui JM, Tometten M, Garcia M, Orsal AS, Cordo-Russo R, et al. A pivotal role for galectin-1 in fetomaternal tolerance. Nat Med (2007) 13:1450-7. doi:10.1038/nm1680

17. Cummings RD, Liu FT. Galectins. 2nd ed. In: Varki A, Cummings R, Esko JD, Freeze H, Stanley P, Bertozzi CR, et al., editors. Essentials of Glycobiology. Woodbury, NY: Cold Spring Harbor Laboratory Press (2009). p. 475-88.

18. Rabinovich GA, Toscano MA. Turning 'sweet' on immunity: galectin-glycan interactions in immune tolerance and inflammation. Nat Rev Immunol (2009) 9:338-52. doi:10.1038/nri2536

19. Than NG, Romero R, Kim CJ, Mcgowen MR, Papp Z, Wildman DE. Galectins: guardians of eutherian pregnancy at the maternal-fetal interface. Trends Endocrinol Metab (2012) 23:23-31. doi:10.1016/j.tem.2011.09.003

20. Brewer CF, Miceli MC, Baum LG. Clusters, bundles, arrays and lattices: novel mechanisms for lectin-saccharide-mediated cellular interactions. Curr Opin Struct Biol (2002) 12:616-23. doi:10.1016/S0959-440X(02)00364-0

21. Than NG, Romero R, Meiri H, Erez O, Xu Y, Tarquini F, et al. PP13, maternal ABO blood groups and the risk assessment of pregnancy complications. PLoS One (2011) 6:e21564. doi:10.1371/journal.pone.0021564

22. Watkins WM. The ABO blood group system: historical background. Transfus Med (2001) 11:243-65. doi:10.1046/j.1365-3148.2001.00321.x

23. Than NG, Romero R, Goodman M, Weckle A, Xing J, Dong Z, et al. A primate subfamily of galectins expressed at the maternal-fetal interface that promote immune cell death. Proc Natl Acad Sci U S A (2009) 106:9731-6. doi:10.1073/pnas.0903568106

24. Stowell SR, Arthur CM, Mehta P, Slanina KA, Blixt O, Leffler H, et al. Galectin-1, -2 , and -3 exhibit differential recognition of sialylated glycans and blood group antigens. J Biol Chem (2008) 283:10109-23. doi:10.1074/jbc.M709545200

25. Stowell SR, Arthur CM, Dias-Baruffi M, Rodrigues LC, Gourdine JP, HeimburgMolinaro J, et al. Innate immune lectins kill bacteria expressing blood group antigen. Nat Med (2010) 16:295-301. doi:10.1038/nm.2103

26. Marionneau S, Cailleau-Thomas A, Rocher J, Le Moullac-Vaidye B, Ruvoen N, Clement $\mathrm{M}$, et al. $\mathrm{ABH}$ and Lewis histo-blood group antigens, a model for the meaning of oligosaccharide diversity in the face of a changing world. Biochimie (2001) 83:565-73. doi:10.1016/S0300-9084(01)01321-9

27. Varki A, Cummings R, Esko JD, Freeze H, Stanley P, Bertozzi CR, et al. Essentials in Glycobiology. Woodbury, NY: Cold Spring Harbor Laboratory Press (2008).

28. Nei M, Rooney AP. Concerted and birth-and-death evolution of multigene families. Annu Rev Genet (2005) 39:121-52. doi:10.1146/annurev.genet.39. 073003.112240

29. Sammar M, Stolk M, Gebhardt S, Pick-Golan E, Meiri H, et al. RNA splicing and DNA polymorphism leading to two shorter sub-forms of placenta protein 13 (PP13) in preeclampsia. Am J Obstet Gynecol (2006) 195(Suppl 1):S141. doi:10.1016/j.ajog.2006.10.494

30. Stolk M, Rebello G, Gebhardt S, Carelse K, Huppertz B, Hahn S, et al. The binding region of the human galectin/placental protein-13 gene, LGALS13, is enriched with nucleotide sequence variation. XV World Congress of the International Society for the Study of Hypertension in Pregnancy: (Hypertension in Pregnancy). (2006). p. i-xii.

31. Bruiners N, Bosman M, Postma A, Gebhardt S, Rebello G, Sammar M, et al. Promoter variant-98A-C of the LGALS13 gene and pre-eclampsia. In: Bevilacqua G, editor. Proceedings of the 8th World Congress of Perinatal Medicine. Lippincott Williams and Wilkins (2007). p. 371-4.

32. Sammar M, Stolk M, Nisemblat S, Gebhardt S, Pick-Golan E, Meiri H, et al. Subforms of PP13 may contribute to marker deficiency in preeclampsia. Placenta (2007) 28(8-9):A67.

33. Rebello G, Bosman M, Postma A, Bruiners N, Sammar M, Meiri H, et al. Genetic changes in LGALS13 support predictive role of PP13 in pregnancy outcome. Placenta (2008) 29(8-9):A79.

34. Gebhardt S, Bruiners N, Hillermann R. A novel exonic variant (221delT) in the LGALS13 gene encoding placental protein 13 (PP13) is associated with preterm labour in a low risk population. J Reprod Immunol (2009) 82:166-73. doi:10.1016/j.jri.2009.07.004

35. Sammar M, Nisamblatt S, Gonen R, Huppertz B, Gizurarson S, Meiri H. The role of the carbohydrate regulating domain (CRD) of placental protein 13 (PP13) in pregnancy evaluated with recombinant PP13 and its DelT221 variant. PLoS ONE (2014) 9:e102832. doi:10.1371/journal.pone.0102832
36. Than NG, Abdul Rahman O, Magenheim R, Nagy B, Fule T, Hargitai B, et al. Placental protein 13 (galectin-13) has decreased placental expression but increased shedding and maternal serum concentrations in patients presenting with preterm pre-eclampsia and HELLP syndrome. Virchows Arch (2008) 453:387-400. doi:10.1007/s00428-008-0658-x

37. Huppertz B, Sammar M, Chefetz I, Neumaier-Wagner P, Bartz C, Meiri H. Longitudinal determination of serum placental protein 13 during development of preeclampsia. Fetal Diagn Ther (2008) 24:230-6. doi:10.1159/000151344

38. Aronow BJ, Richardson BD, Handwerger S. Microarray analysis of trophoblast differentiation: gene expression reprogramming in key gene function categories. Physiol Genomics (2001) 6:105-16.

39. Loregger T, Pollheimer J, Knofler M. Regulatory transcription factors controlling function and differentiation of human trophoblast - a review. Placenta (2003) 24(Suppl A):S104-10. doi:10.1053/plac.2002.0929

40. Kudo Y, Boyd CA, Sargent IL, Redman CW, Lee JM, Freeman TC. An analysis using DNA microarray of the time course of gene expression during syncytialization of a human placental cell line (BeWo). Placenta (2004) 25:479-88. doi:10.1016/j.placenta.2003.12.001

41. Ellery PM, Cindrova-Davies T, Jauniaux E, Ferguson-Smith AC, Burton GJ. Evidence for transcriptional activity in the syncytiotrophoblast of the human placenta. Placenta (2009) 30:329-34. doi:10.1016/j.placenta.2009.01.002

42. Bischof P, Irminger-Finger I. The human cytotrophoblastic cell, a mononuclear chameleon. Int J Biochem Cell Biol (2005) 37:1-16. doi:10.1016/j.biocel.2004. 05.014

43. Ahmed MS, Aleksunes LM, Boeuf P, Chung MK, Daoud G, Desoye G, et al. IFPA meeting 2012 workshop report II: epigenetics and imprinting in the placenta, growth factors and villous trophoblast differentiation, role of the placenta in regulating fetal exposure to xenobiotics during pregnancy, infection and the placenta. Placenta (2013) 34(Suppl):S6-10. doi:10.1016/j.placenta. 2012.11.020

44. Orendi K, Gauster M, Moser G, Meiri H, Huppertz B. The choriocarcinoma cell line BeWo: syncytial fusion and expression of syncytium-specific proteins. Reproduction (2010) 140:759-66. doi:10.1530/REP-10-0221

45. Than NG, Romero R, Xu Y, Erez O, Xu Z, Bhatti G, et al. Evolutionary origins of the placental expression of chromosome 19 cluster galectins and their complex dysregulation in preeclampsia. Placenta (2014). doi:10.1016/j.placenta.2014. 07.015

46. Janatpour MJ, Utset MF, Cross JC, Rossant J, Dong J, Israel MA, et al A repertoire of differentially expressed transcription factors that offers insight into mechanisms of human cytotrophoblast differentiation. Dev Genet (1999) 25:146-57. doi:10.1002/(SICI)1520-6408(1999)25:2<146::AIDDVG9>3.0.CO;2-K

47. Lee X, Keith JC Jr, Stumm N, Moutsatsos I, Mccoy JM, Crum CP, et al. Downregulation of placental syncytin expression and abnormal protein localization in pre-eclampsia. Placenta (2001) 22:808-12. doi:10.1053/plac.2001.0722

48. Chen CP, Chen CY, Yang YC, Su TH, Chen H. Decreased placental GCM1 (glial cells missing) gene expression in pre-eclampsia. Placenta (2004) 25:413-21. doi:10.1016/j.placenta.2003.10.014

49. Burton GJ, Jauniaux E. Placental oxidative stress: from miscarriage to preeclampsia. J Soc Gynecol Investig (2004) 11:342-52. doi:10.1016/j.jsgi.2004. 03.003

50. Redman CW, Sargent IL. Immunology of pre-eclampsia. Am J Reprod Immunol (2010) 63:534-43. doi:10.1111/j.1600-0897.2010.00831.x

51. Sibai B, Dekker G, Kupferminc M. Pre-eclampsia. Lancet (2005) 365:785-99. doi:10.1016/S0140-6736(05)17987-2

52. von Dadelszen P, Magee LA, Roberts JM. Subclassification of preeclampsia. Hypertens Pregnancy (2003) 22:143-8. doi:10.1081/PRG-120021060

53. Than NG, Vaisbuch E, Kim CJ, Mazaki-Tovi S, Erez O, Yeo L, et al. Early-onset preeclampsia and HELLP syndrome: an overview. In: Preedy VR, editor. Handbook of Growth and Growth Monitoring in Health and Disease. Heidelberg: Springer (2012). p. 1867-91.

54. Haram K, Svendsen E, Abildgaard U. The HELLP syndrome: clinical issues and management. A review. BMC Pregnancy Childbirth (2009) 9:8. doi:10.1186/ 1471-2393-9-8

55. Roberts JM, Hubel CA. The two stage model of preeclampsia: variations on the theme. Placenta (2009) 30(Suppl A):S32-7. doi:10.1016/j.placenta.2008.11.009

56. Ness RB, Roberts JM. Heterogeneous causes constituting the single syndrome of preeclampsia: a hypothesis and its implications. Am J Obstet Gynecol (1996) 175:1365-70. doi:10.1016/S0002-9378(96)70056-X 
57. Moldenhauer JS, Stanek J, Warshak C, Khoury J, Sibai B. The frequency and severity of placental findings in women with preeclampsia are gestational age dependent. Am J Obstet Gynecol (2003) 189:1173-7. doi:10.1067/S00029378(03)00576-3

58. Sebire NJ, Goldin RD, Regan L. Term preeclampsia is associated with minimal histopathological placental features regardless of clinical severity. J Obstet Gynecol (2005) 25:117-8. doi:10.1080/014436105400041396

59. Nishizawa H, Pryor-Koishi K, Kato T, Kowa H, Kurahashi H, Udagawa Y. Microarray analysis of differentially expressed fetal genes in placental tissue derived from early and late onset severe pre-eclampsia. Placenta (2007) 28:487-97. doi:10.1016/j.placenta.2006.05.010

60. Sitras V, Paulssen RH, Gronaas H, Leirvik J, Hanssen TA, Vartun A, et al. Differential placental gene expression in severe preeclampsia. Placenta (2009) 30:424-33. doi:10.1016/j.placenta.2009.01.012

61. Ogge G, Chaiworapongsa T, Romero R, Hussein Y, Kusanovic JP, Yeo L, et al. Placental lesions associated with maternal underperfusion are more frequent in early-onset than in late-onset preeclampsia. J Perinat Med (2011) 39:641-52. doi:10.1515/JPM.2011.098

62. Brosens IA. Morphological changes in the utero-placental bed in pregnancy hypertension. Clin Obstet Gynaecol (1977) 4:573-93.

63. Brosens I, Pijnenborg R, Vercruysse L, Romero R. The "great obstetrical syndromes" are associated with disorders of deep placentation. Am J Obstet Gynecol (2011) 204:193-201. doi:10.1016/j.ajog.2010.08.009

64. Genbacev O, Joslin R, Damsky CH, Polliotti BM, Fisher SJ. Hypoxia alters early gestation human cytotrophoblast differentiation/invasion in vitro and models the placental defects that occur in preeclampsia. JClin Invest (1996) 97:540-50. doi:10.1172/JCI118447

65. Crocker I. Gabor Than award lecture 2006: pre-eclampsia and villous trophoblast turnover: perspectives and possibilities. Placenta (2007) 28(Suppl A):S4-13. doi:10.1016/j.placenta.2007.01.016

66. Burton GJ, Woods AW, Jauniaux E, Kingdom JC. Rheological and physiological consequences of conversion of the maternal spiral arteries for uteroplacental blood flow during human pregnancy. Placenta (2009) 30:473-82. doi:10.1016/j.placenta.2009.02.009

67. Cindrova-Davies T. Gabor Than award lecture 2008: pre-eclampsia - from placental oxidative stress to maternal endothelial dysfunction. Placenta (2009) 30(Suppl A):S55-65. doi:10.1016/j.placenta.2008.11.020

68. Maynard SE, Min JY, Merchan J, Lim KH, Li J, Mondal S, et al. Excess placental soluble fms-like tyrosine kinase 1 (sFlt1) may contribute to endothelial dysfunction, hypertension, and proteinuria in preeclampsia. J Clin Invest (2003) 111:649-58. doi:10.1172/JCI17189

69. Chaiworapongsa T, Romero R, Espinoza J, Bujold E, Mee KY, Goncalves LF, et al. Evidence supporting a role for blockade of the vascular endothelial growth factor system in the pathophysiology of preeclampsia. Young investigator award. Am J Obstet Gynecol (2004) 190:1541-7. doi:10.1016/j.ajog.2004.03.043

70. Venkatesha S, Toporsian M, Lam C, Hanai J, Mammoto T, Kim YM, et al. Soluble endoglin contributes to the pathogenesis of preeclampsia. Nat Med (2006) 12:642-9. doi:10.1038/nm1429

71. Sammar M, Nisemblat S, Fleischfarb Z, Golan A, Sadan O, Meiri H, et al. Placenta-bound and body fluid PP13 and its mRNA in normal pregnancy compared to preeclampsia, HELLP and preterm delivery. Placenta (2011) 32(Suppl):S30-6. doi:10.1016/j.placenta.2010.09.006

72. Sekizawa A, Purwosunu Y, Yoshimura S, Nakamura M, Shimizu H, Okai T, et al PP13 mRNA expression in trophoblasts from preeclamptic placentas. Reprod Sci (2009) 16:408-13. doi:10.1177/1933719108328615

73. Balogh A, Pozsgay J, Matko J, Dong Z, Kim CJ, Varkonyi T, et al. Placental protein 13 (PP13/galectin-13) undergoes lipid raft-associated subcellular redistribution in the syncytiotrophoblast in preterm preeclampsia and HELLP syndrome. Am J Obstet Gynecol (2011) 205:156.e-151.e. doi:10.1016/j.ajog.2011. 03.023

74. Lanzetti L. Actin in membrane trafficking. Curr Opin Cell Biol (2007) 19:453-8. doi:10.1016/j.ceb.2007.04.017

75. Anitei M, Hoflack B. Bridging membrane and cytoskeleton dynamics in the secretory and endocytic pathways. Nat Cell Biol (2012) 14:11-9. doi:10.1038/ ncb2409

76. Nickel W. The mystery of nonclassical protein secretion. A current view on cargo proteins and potential export routes. Eur J Biochem (2003) 270:2109-19. doi:10.1046/j.1432-1033.2003.03577.x
77. Leffler H, Carlsson S, Hedlund M, Qian Y, Poirier F. Introduction to galectins. Glycoconj J (2004) 19:433-40. doi:10.1023/B:GLYC.0000014072. 34840.04

78. Vasta GR, Ahmed H, Nita-Lazar M, Banerjee A, Pasek M, Shridhar S, et al. Galectins as self/non-self recognition receptors in innate and adaptive immunity: an unresolved paradox. Front Immunol (2012) 3:199. doi:10.3389/fimmu. 2012.00199

79. Betz WJ, Bewick GS. Optical analysis of synaptic vesicle recycling at the frog neuromuscular junction. Science (1992) 255:200-3. doi:10.1126/science. 1553547

80. Miklavc P, Wittekindt OH, Felder E, Dietl P. Ca2+-dependent actin coating of lamellar bodies after exocytotic fusion: a prerequisite for content release and kiss-and-run. Ann N Y Acad Sci (2009) 1152:43-52. doi:10.1111/j.1749-6632. 2008.03989.x

81. Perone MJ, Larregina AT, Shufesky WJ, Papworth GD, Sullivan ML, Zahorchak AF, et al. Transgenic galectin-1 induces maturation of dendritic cells that elicit contrasting responses in naive and activated T cells. J Immunol (2006) 176:7207-20. doi:10.4049/jimmunol.176.12.7207

82. Klibi J, Niki T, Riedel A, Pioche-Durieu C, Souquere S, Rubinstein E, et al. Blood diffusion and Th1-suppressive effects of galectin-9-containing exosomes released by Epstein-Barr virus-infected nasopharyngeal carcinoma cells. Blood (2009) 113:1957-66. doi:10.1182/blood-2008-02-142596

83. Welton JL, Khanna S, Giles PJ, Brennan P, Brewis IA, Staffurth J, et al. Proteomics analysis of bladder cancer exosomes. Mol Cell Proteomics (2010) 9:1324-38. doi:10.1074/mcp.M000063-MCP201

84. Lee TL, Lin YC, Mochitate K, Grinnell F. Stress-relaxation of fibroblasts in collagen matrices triggers ectocytosis of plasma membrane vesicles containing actin, annexins II and VI, and beta 1 integrin receptors. J Cell Sci (1993) 105(Pt 1):167-77.

85. Danielsen EM, van Deurs B, Hansen GH. "Nonclassical” secretion of annexin A2 to the lumenal side of the enterocyte brush border membrane. Biochemistry (2003) 42:14670-6. doi:10.1021/bi0355239

86. Keryer-Bibens C, Pioche-Durieu C, Villemant C, Souquere S, Nishi N, Hirashima M, et al. Exosomes released by EBV-infected nasopharyngeal carcinoma cells convey the viral latent membrane protein 1 and the immunomodulatory protein galectin 9. BMC Cancer (2006) 6:283. doi:10.1186/1471-24076-283

87. Liu FT, Hsu DK, Zuberi RI, Kuwabara I, Chi EY, Henderson WR Jr. Expression and function of galectin-3, a beta-galactoside-binding lectin, in human monocytes and macrophages. Am J Pathol (1995) 147:1016-28.

88. Savina A, Furlan M, Vidal M, Colombo MI. Exosome release is regulated by a calcium-dependent mechanism in K562 cells. J Biol Chem (2003) 278:20083-90. doi:10.1074/jbc.M301642200

89. Schmidt A, Hall MN. Signaling to the actin cytoskeleton. Annu Rev Cell Dev Biol (1998) 14:305-38. doi:10.1146/annurev.cellbio.14.1.305

90. Beaudoin AR, Grondin G. Shedding of vesicular material from the cell surface of eukaryotic cells: different cellular phenomena. Biochim Biophys Acta (1991) 1071:203-19. doi:10.1016/0304-4157(91)90014-N

91. Stenbeck G, Coxon FP. Role of vesicular trafficking in skeletal dynamics. Curr Opin Pharmacol (2014) 16C:7-14. doi:10.1016/j.coph.2014.01.003

92. Walsh TP, Weber A, Davis K, Bonder E, Mooseker M. Calcium dependence of villin-induced actin depolymerization. Biochemistry (1984) 23:6099-102. doi:10.1021/bi00320a030

93. Noegel A, Witke W, Schleicher M. Calcium-sensitive non-muscle alpha-actinin contains EF-hand structures and highly conserved regions. FEBS Lett (1987) 221:391-6. doi:10.1016/0014-5793(87)80962-6

94. Thiel C, Osborn M, Gerke V. The tight association of the tyrosine kinase substrate annexin II with the submembranous cytoskeleton depends on intact p11and $\mathrm{Ca}(2+)$-binding sites. J Cell Sci (1992) 103(Pt 3):733-42.

95. Gerke V, Creutz CE, Moss SE. Annexins: linking Ca2+ signalling to membrane dynamics. Nat Rev Mol Cell Biol (2005) 6:449-61. doi:10.1038/nrm1661

96. Gutierrez LM. New insights into the role of the cortical cytoskeleton in exocytosis from neuroendocrine cells. Int Rev Cell Mol Biol (2012) 295:109-37. doi:10.1016/B978-0-12-394306-4.00009-5

97. Burton GJ, Yung HW, Cindrova-Davies T, Charnock-Jones DS. Placental endoplasmic reticulum stress and oxidative stress in the pathophysiology of unexplained intrauterine growth restriction and early onset preeclampsia. Placenta (2009) 30(Suppl A):S43-8. doi:10.1016/j.placenta.2008.11.003 
98. Grimpel YI, Kivity V, Cohen A, Meiri H, Sammar M, Gonen R, et al. Effects of calcium, magnesium, low-dose aspirin and low-molecular-weight heparin on the release of PP13 from placental explants. Placenta (2011) 32(Suppl):S55-64. doi:10.1016/j.placenta.2010.11.019

99. Duffy S, Macvicar BA. In vitro ischemia promotes calcium influx and intracellular calcium release in hippocampal astrocytes. J Neurosci (1996) 16:71-81.

100. Maus M, Medgyesi D, Kiss E, Schneider AE, Enyedi A, Szilagyi N, et al. B cell receptor-induced $\mathrm{Ca} 2+$ mobilization mediates $\mathrm{F}$-actin rearrangements and is indispensable for adhesion and spreading of B lymphocytes. J Leukoc Biol (2013) 93:537-47. doi:10.1189/jlb.0312169

101. Matzinger P. An innate sense of danger. Ann N Y Acad Sci (2002) 961:341-2. doi:10.1111/j.1749-6632.2002.tb03118.x

102. Bianchi ME. DAMPs, PAMPs and alarmins: all we need to know about danger. J Leukoc Biol (2007) 81:1-5. doi:10.1189/jlb.0306164

103. Kim YM, Romero R, Oh SY, Kim CJ, Kilburn BA, Armant DR, et al. Toll-like receptor 4: a potential link between "danger signals," the innate immune system, and preeclampsia? Am J Obstet Gynecol (2005) 193:921-7. doi:10.1016/j. ajog.2005.07.076

104. Bonney EA. Preeclampsia: a view through the danger model. J Reprod Immunol (2007) 76:68-74. doi:10.1016/j.jri.2007.03.006

105. Than NG, Erez O, Wildman DE, Tarca AL, Edwin SS, Abbas A, et al. Severe preeclampsia is characterized by increased placental expression of galectin-1. J Matern Fetal Neonatal Med (2008) 21:429-42. doi:10.1080/ 14767050802041961

106. Rabinovich GA, Baum LG, Tinari N, Paganelli R, Natoli C, Liu FT, et al. Galectins and their ligands: amplifiers, silencers or tuners of the inflammatory response? Trends Immunol (2002) 23:313-20. doi:10.1016/S1471-4906(02) 02232-9

107. Rabinovich GA, Toscano MA, Jackson SS, Vasta GR. Functions of cell surface galectin-glycoprotein lattices. Curr Opin Struct Biol (2007) 17:513-20. doi:10.1016/j.sbi.2007.09.002

108. Sato S, St-Pierre C, Bhaumik P, Nieminen J. Galectins in innate immunity: dual functions of host soluble beta-galactoside-binding lectins as damage-associated molecular patterns (DAMPs) and as receptors for pathogen-associated molecular patterns (PAMPs). Immunol Rev (2009) 230:172-87. doi:10.1111/j.1600065X.2009.00790.x

109. Perillo NL, Pace KE, Seilhamer JJ, Baum LG. Apoptosis of T cells mediated by galectin-1. Nature (1995) 378:736-9. doi:10.1038/378736a0

110. Hsu DK, Yang RY, Liu FT. Galectins in apoptosis. Methods Enzymol (2006) 417:256-73. doi:10.1016/S0076-6879(06)17018-4

111. Kopcow HD, Rosetti F, Leung Y, Allan DS, Kutok JL, Strominger JL. T cell apoptosis at the maternal-fetal interface in early human pregnancy, involvement of galectin-1. Proc Natl Acad Sci U S A (2008) 105:18472-7. doi:10.1073/pnas.0809233105

112. Than NG, Romero R, Erez O, Weckle A, Tarca AL, Hotra J, et al. Emergence of hormonal and redox regulation of galectin-1 in placental mammals: implication in maternal-fetal immune tolerance. Proc Natl Acad Sci U S A (2008) 105:15819-24. doi:10.1073/pnas.0807606105

113. Spinillo A, Capuzzo E, Baltaro F, Piazzi G, Iasci A. Case-control study of maternal blood group and severe pre-eclampsia. J Hum Hypertens (1995) 9: 623-5.

114. Hiltunen LM, Laivuori H, Rautanen A, Kaaja R, Kere J, Krusius T, et al. Blood group $\mathrm{AB}$ and factor $\mathrm{V}$ Leiden as risk factors for pre-eclampsia: a population-based nested case-control study. Thromb Res (2009) 124:167-73. doi:10.1016/j.thromres.2008.11.012

115. Medalie JH, Levene C, Papier C, Goldbourt U, Dreyfuss F, Oron D, et al. Blood groups, myocardial infarction and angina pectoris among 10,000 adult males. N Engl J Med (1971) 285:1348-53. doi:10.1056/NEJM197112092852404

116. Meade TW, Cooper JA, Stirling Y, Howarth DJ, Ruddock V, Miller GJ. Factor VIII, ABO blood group and the incidence of ischaemic heart disease. $\mathrm{Br}$ J Haematol (1994) 88:601-7. doi:10.1111/j.1365-2141.1994.tb05079.x

117. Koster T, Blann AD, Briet E, Vandenbroucke JP, Rosendaal FR. Role of clotting factor VIII in effect of von Willebrand factor on occurrence of deep-vein thrombosis. Lancet (1995) 345:152-5. doi:10.1016/S0140-6736(95) 90166-3

118. O'Donnell J, Laffan MA. The relationship between ABO histo-blood group, factor VIII and von Willebrand factor. Transfus Med (2001) 11:343-51. doi:10.1046/j.1365-3148.2001.00315.x
119. McCombs HL, Craig JM. Decidual necrosis in normal pregnancy. Obstet Gynecol (1964) 24:436-42.

120. Carter AM. Comparative studies of placentation and immunology in nonhuman primates suggest a scenario for the evolution of deep trophoblast invasion and an explanation for human pregnancy disorders. Reproduction (2011) 141:391-6. doi:10.1530/REP-10-0530

121. Carter AM, Pijnenborg R. Evolution of invasive placentation with special reference to non-human primates. Best Pract Res Clin Obstet Gynaecol (2011) 25:249-57. doi:10.1016/j.bpobgyn.2010.10.010

122. Pijnenborg R, Vercruysse L, Carter AM. Deep trophoblast invasion and spiral artery remodelling in the placental bed of the lowland gorilla. Placenta (2011) 32:586-91. doi:10.1016/j.placenta.2011.05.007

123. Pijnenborg R, Vercruysse L, Carter AM. Deep trophoblast invasion and spiral artery remodelling in the placental bed of the chimpanzee. Placenta (2011) 32:400-8. doi:10.1016/j.placenta.2011.02.009

124. Than NG. PP13, decidual zones of necrosis, and spiral artery remodeling - preeclampsia revisited? Reprod Sci (2012) 19:14-5. doi:10.1177/ 1933719111431678

125. Bulmer JN, Pace D, Ritson A. Immunoregulatory cells in human decidua: morphology, immunohistochemistry and function. Reprod Nutr Dev (1988) 28:1599-613. doi:10.1051/rnd:19881006

126. Mor G, Cardenas I. The immune system in pregnancy: a unique complexity. Am J Reprod Immunol (2010) 63:425-33. doi:10.1111/j.1600-0897.2010.00836.x

127. Mor G, Cardenas I, Abrahams V, Guller S. Inflammation and pregnancy: the role of the immune system at the implantation site. Ann N Y Acad Sci (2011) 1221:80-7. doi:10.1111/j.1749-6632.2010.05938.x

128. Pijnenborg R, Vercruysse L, Hanssens M. The uterine spiral arteries in human pregnancy: facts and controversies. Placenta (2006) 27:939-58. doi:10.1016/j. placenta.2005.12.006

129. Saito S, Nakashima A, Shima T, Ito M. Th1/Th2/Th17 and regulatory T-cell paradigm in pregnancy. Am J Reprod Immunol (2010) 63:601-10. doi:10.1111/ j.1600-0897.2010.00852.x

130. Harris LK. IFPA Gabor Than award lecture: transformation of the spiral arteries in human pregnancy: key events in the remodelling timeline. Placenta (2011) 32(Suppl B):S154-8. doi:10.1016/j.placenta.2010.11.018

131. Szekeres-Bartho J, Polgar B. PIBF: the double edged sword. Pregnancy and tumor. Am J Reprod Immunol (2010) 64:77-86. doi:10.1111/j.1600-0897.2010. 00833.x

132. Nagamatsu T, Schust DJ. The immunomodulatory roles of macrophages at the maternal-fetal interface. Reprod Sci (2010) 17:209-18. doi:10.1177/ 1933719109349962

133. Abrahams VM, Straszewski-Chavez SL, Guller S, Mor G. First trimester trophoblast cells secrete Fas ligand which induces immune cell apoptosis. Mol Hum Reprod (2004) 10:55-63. doi:10.1093/molehr/gah006

134. Dong M, Ding G, Zhou J, Wang H, Zhao Y, Huang H. The effect of trophoblasts on T lymphocytes: possible regulatory effector molecules - a proteomic analysis. Cell Physiol Biochem (2008) 21:463-72. doi:10.1159/000129639

135. Hiby SE, Walker JJ, O'Shaughnessy KM, Redman CW, Carrington M, Trowsdale $\mathrm{J}$, et al. Combinations of maternal KIR and fetal HLA-C genes influence the risk of preeclampsia and reproductive success. J Exp Med (2004) 200:957-65. doi:10.1084/jem.20041214

136. Hunt JS, Petroff MG, Mcintire RH, Ober C. HLA-G and immune tolerance in pregnancy. FASEB J (2005) 19:681-93. doi:10.1096/fj.04-2078rev

137. Burton GJ. Oxygen, the Janus gas; its effects on human placental development and function. JAnat (2009) 215:27-35. doi:10.1111/j.1469-7580.2008.00978.x

138. Jauniaux E, Watson AL, Hempstock J, Bao YP, Skepper JN, Burton GJ. Onset of maternal arterial blood flow and placental oxidative stress. A possible factor in human early pregnancy failure. Am J Pathol (2000) 157:2111-22. doi:10.1016/S0002-9440(10)64849-3

139. Jeschke U, Reimer T, Bergemann C, Wiest I, Schulze S, Friese K, et al. Binding of galectin-1 (gal-1) on trophoblast cells and inhibition of hormone production of trophoblast tumor cells in vitro by gal-1. Histochem Cell Biol (2004) 121:501-8. doi:10.1007/s00418-004-0660-6

140. Jeschke U, Karsten U, Wiest I, Schulze S, Kuhn C, Friese K, et al. Binding of galectin-1 (gal-1) to the Thomsen-Friedenreich (TF) antigen on trophoblast cells and inhibition of proliferation of trophoblast tumor cells in vitro by gal-1 or an anti-TF antibody. Histochem Cell Biol (2006) 126:437-44. doi:10.1007/s00418-006-0178-1 
141. Fischer I, Redel S, Hofmann S, Kuhn C, Friese K, Walzel H, et al. Stimulation of syncytium formation in vitro in human trophoblast cells by galectin-1. Placenta (2010) 31:825-32. doi:10.1016/j.placenta.2010.06.016

142. Gizurarson S, Huppertz B, Osol G, Skarphedinsson JO, Mandala M, Meiri H. Effects of placental protein 13 on the cardiovascular system in gravid and non-gravid rodents. Fetal Diagn Ther (2013) 33:257-64. doi:10.1159/ 000345964

143. Gizurarson S, Sigurdardottir ER, Meiri H, Huppertz B, Sammar M, SharabaniNov A, et al. Placental protein 13 (PP13) preconditions the uterine vasculature in pregnant rats: potential benefit in preeclampsia and IUGR. Fetal Diagn Ther (2014, submitted)

144. Shimizu H, Sekizawa A, Purwosunu Y, Nakamura M, Farina A, Rizzo N, et al. PP13 mRNA expression in the cellular component of maternal blood as a marker for preeclampsia. Prenat Diagn (2009) 29:1231-6. doi:10.1002/pd. 2380

145. Farina A, Zucchini C, Sekizawa A, Purwosunu Y, De Sanctis P, Santarsiero $\mathrm{G}$, et al. Performance of messenger RNAs circulating in maternal blood in the prediction of preeclampsia at 10-14 weeks. Am J Obstet Gynecol (2010) 203(575):e571-7. doi:10.1016/j.ajog.2010.07.043

146. Madar-Shapiro L, Trachtenhertz E, Karadi I, Cohen R, Poon CL, Rolings D, et al. Determination of PP13 mRNA in pregnant sera from first, second and third trimesters in normal pregnancy and in preeclampsia. (Forthcoming).

147. Huppertz B, Meiri H, Gizurarson S, Osol G, Sammar M. Placental protein 13 (PP13): a new biological target shifting individualized risk assessment to personalized drug design combating pre-eclampsia. Hum Reprod Update (2013) 19:391-405. doi:10.1093/humupd/dmt003

148. Nicolaides KH, Bindra R, Turan OM, Chefetz I, Sammar M, Meiri H, et al. A novel approach to first-trimester screening for early pre-eclampsia combining serum PP-13 and Doppler ultrasound. Ultrasound Obstet Gynecol (2006) 27:13-7. doi:10.1002/uog.2686

149. Chafetz I, Kuhnreich I, Sammar M, Tal Y, Gibor Y, Meiri H, et al. Firsttrimester placental protein 13 screening for preeclampsia and intrauterine growth restriction. Am J Obstet Gynecol (2007) 197:35-7. doi:10.1016/j.ajog. 2007.02.025

150. Spencer K, Cowans NJ, Chefetz I, Tal J, Meiri H. First-trimester maternal serum PP-13, PAPP-A and second-trimester uterine artery Doppler pulsatility index as markers of pre-eclampsia. Ultrasound Obstet Gynecol (2007) 29:128-34. doi:10.1002/uog.3876

151. Gonen R, Shahar R, Grimpel YI, Chefetz I, Sammar M, Meiri H, et al. Placental protein 13 as an early marker for pre-eclampsia: a prospective longitudinal study. BJOG (2008) 115:1465-72. doi:10.1111/j.1471-0528.2008. 01902.x

152. Romero R, Kusanovic JP, Than NG, Erez O, Gotsch F, Espinoza J, et al. Firsttrimester maternal serum PP13 in the risk assessment for preeclampsia. Am J Obstet Gynecol (2008) 199:122-122. doi:10.1016/j.ajog.2008.01.013

153. Akolekar R, Syngelaki A, Beta J, Kocylowski R, Nicolaides KH. Maternal serum placental protein 13 at 11-13 weeks of gestation in preeclampsia. Prenat Diagn (2009) 29:1103-8. doi:10.1002/pd.2375

154. Khalil A, Cowans NJ, Spencer K, Goichman S, Meiri H, Harrington K. First trimester maternal serum placental protein 13 for the prediction of preeclampsia in women with a priori high risk. Prenat Diagn (2009) 29:781-9. doi:10.1002/pd.2287

155. Audibert F, Boucoiran I, An N, Aleksandrov N, Delvin E, Bujold E, et al. Screening for preeclampsia using first-trimester serum markers and uterine artery Doppler in nulliparous women. Am J Obstet Gynecol (2010) 203:383-8. doi:10.1016/j.ajog.2010.06.014

156. Wortelboer EJ, Koster MP, Cuckle HS, Stoutenbeek PH, Schielen PC, Visser GH. First-trimester placental protein 13 and placental growth factor: markers for identification of women destined to develop early-onset pre-eclampsia. BJOG (2010) 117:1384-9. doi:10.1111/j.1471-0528.2010.02690.x

157. Akolekar R, Syngelaki A, Sarquis R, Zvanca M, Nicolaides KH. Prediction of early, intermediate and late pre-eclampsia from maternal factors, biophysical and biochemical markers at 11-13 weeks. Prenat Diagn (2011) 31:66-74. doi:10.1002/pd.2660

158. Odibo AO, Zhong Y, Goetzinger KR, Odibo L, Bick JL, Bower CR, et al. Firsttrimester placental protein 13, PAPP-A, uterine artery Doppler and maternal characteristics in the prediction of pre-eclampsia. Placenta (2011) 32:598-602. doi:10.1016/j.placenta.2011.05.006
159. Di Lorenzo G, Ceccarello M, Cecotti V, Ronfani L, Monasta L, Vecchi Brumatti L, et al. First trimester maternal serum PIGF, free beta-hCG, PAPP-A, PP-13, uterine artery Doppler and maternal history for the prediction of preeclampsia. Placenta (2012) 33:495-501. doi:10.1016/j.placenta.2012.03.003

160. El Sherbiny WS, Soliman A, Nasr AS. Placental protein 13 as an early predictor in Egyptian patients with preeclampsia, correlation to risk, and association with outcome. J Investig Med (2012) 60:818-22. doi:10.231/JIM.0b013e31824e9a68

161. Moslemi Zadeh N, Naghshvar F, Peyvandi S, Gheshlaghi P, Ehetshami S. PP13 and PAPP-A in the first and second trimesters: predictive factors for preeclampsia? ISRN Obstet Gynecol (2012) 2012:263871. doi:10.5402/2012/263871

162. Myatt L, Clifton RG, Roberts JM, Spong CY, Hauth JC, Varner MW, et al. Firsttrimester prediction of preeclampsia in nulliparous women at low risk. Obstet Gynecol (2012) 119:1234-42. doi:10.1097/AOG.0b013e3182571669

163. Schneuer FJ, Nassar N, Khambalia AZ, Tasevski V, Guilbert C, Ashton AW, et al. First trimester screening of maternal placental protein 13 for predicting preeclampsia and small for gestational age: in-house study and systematic review. Placenta (2012) 33:735-40. doi:10.1016/j.placenta.2012.05.012

164. Svirsky R, Meiri H, Herzog A, Kivity V, Cuckle H, Maymon R. First trimester maternal serum placental protein 13 levels in singleton vs. twin pregnancies with and without severe pre-eclampsia. J Perinat Med (2013) 41:561-6. doi:10.1515/jpm-2013-0011

165. Cuckle HS. Screening for pre-eclampsia - lessons from aneuploidy screening. Placenta (2011) 32(Suppl):S42-8. doi:10.1016/j.placenta.2010.07.015

166. Cowans NJ, Stamatopoulou A, Khalil A, Spencer K. PP13 as a marker of pre-eclampsia: a two platform comparison study. Placenta (2011) 32(Suppl):S37-41. doi:10.1016/j.placenta.2010.08.014

167. Meiri H, Sammar M, Herzog A, Grimpel YI, Fihaman G, Cohen A, et al. Prediction of preeclampsia by placental protein 13 and background risk factors and its prevention by aspirin. J Perinat Med (2014). doi:10.1515/jpm-2013-0298

168. Spencer K, Cowans NJ, Chefetz I, Tal J, Kuhnreich I, Meiri H. Second-trimester uterine artery Doppler pulsatility index and maternal serum PP13 as markers of pre-eclampsia. Prenat Diagn (2007) 27:258-63. doi:10.1002/pd.1664

169. Kuc S, Wortelboer EJ, van Rijn BB, Franx A, Visser GH, Schielen PC. Evaluation of 7 serum biomarkers and uterine artery Doppler ultrasound for firsttrimester prediction of preeclampsia: a systematic review. Obstet Gynecol Surv (2011) 66:225-39. doi:10.1097/OGX.0b013e3182227027

170. Poon LC, Akolekar R, Lachmann R, Beta J, Nicolaides KH. Hypertensive disorders in pregnancy: screening by biophysical and biochemical markers at 11-13 weeks. Ultrasound Obstet Gynecol (2010) 35:662-70. doi:10.1002/uog.7628

171. Parra-Cordero M, Rodrigo R, Barja P, Bosco C, Rencoret G, SepulvedaMartinez A, et al. Prediction of early and late pre-eclampsia from maternal characteristics, uterine artery Doppler and markers of vasculogenesis during first trimester of pregnancy. Ultrasound Obstet Gynecol (2013) 41:538-44. doi:10.1002/uog.12264

172. Poon LC, Syngelaki A, Akolekar R, Lai J, Nicolaides KH. Combined screening for preeclampsia and small for gestational age at 11-13 weeks. Fetal Diagn Ther (2013) 33:16-27. doi:10.1159/000341712

173. Nicolaides KH. Turning the pyramid of prenatal care. Fetal Diagn Ther (2011) 29:183-96. doi:10.1159/000324320

174. Khalil A, Cowans NJ, Spencer K, Goichman S, Meiri H, Harrington K. First-trimester markers for the prediction of pre-eclampsia in women with a-priori high risk. Ultrasound Obstet Gynecol (2010) 35:671-9. doi:10.1002/ uog.7559

175. Conde-Agudelo A, Villar J, Lindheimer M. World Health Organizaton systematic review of screening tests for preeclampsia. Obstet Gynecol (2004) 104:1367-91. doi:10.1097/01.AOG.0000147599.47713.5d

176. Conde-Agudelo A, Romero R, Lindheimer M. Tests to predict preeclampsia. Third ed. In: Lindheimer MD, Roberts JM, Cunningham FG, editors. Chesley's Hypertensive Disorders in Pregnancy. San Diego, CA: Academic Press Inc (2009). p. 191-214.

177. Palomaki GE, Wright DE, Summers AM, Neveux LM, Meier C, O’Donnell A, et al. Repeated measurement of pregnancy-associated plasma protein-A (PAPP-A) in Down syndrome screening: a validation study. Prenat Diagn (2006) 26:730-9. doi:10.1002/pd.1497

178. Chaiworapongsa T, Romero R, Kim YM, Kim GJ, Kim MR, Espinoza J, et al. Plasma soluble vascular endothelial growth factor receptor-1 concentration is elevated prior to the clinical diagnosis of pre-eclampsia. J Matern Fetal Neonatal Med (2005) 17:3-18. doi:10.1080/14767050400028816 
179. Chaiworapongsa T, Romero R, Korzeniewski SJ, Kusanovic JP, Soto E, Lam J, et al. Maternal plasma concentrations of angiogenic/antiangiogenic factors in the third trimester of pregnancy to identify the patient at risk for stillbirth at or near term and severe late preeclampsia. Am J Obstet Gynecol (2013) 208:e281-7. doi:10.1016/j.ajog.2013.01.016

180. Nucci M, Poon LC, Demirdjian G, Darbouret B, Nicolaides KH. Maternal serum placental growth factor isoforms 1 and 2 at 11-13, 20-24 and 30-34 weeks' gestation in late-onset pre-eclampsia and small for gestational age neonates. Fetal Diagn Ther (2014) 35:249-57. doi:10.1159/000358595

181. Huppertz B, Siwetz M, Herzog A, Cohen R, Schlembah D, Meiri H. Longitudinal changes of placental protein 13 (PP13) in placenta-associated pregnancy disorders. In: Yagel S, editor. SGI Summit, From Implantation to Parturition, New Frontiers in Women's Health. Jerusalem: Hadassah Hebrew University Medical Center (2013).

182. Goswami D, Tannetta DS, Magee LA, Fuchisawa A, Redman CW, Sargent IL, et al. Excess syncytiotrophoblast microparticle shedding is a feature of earlyonset pre-eclampsia, but not normotensive intrauterine growth restriction. Placenta (2006) 27:56-61. doi:10.1016/j.placenta.2004.11.007

183. Lewis S, Clarke M. Forest plots: trying to see the wood and the trees. BMJ (2001) 322:1479-80. doi:10.1136/bmj.322.7300.1479

184. Huppertz B. Placental origins of preeclampsia: challenging the current hypothesis. Hypertension (2008) 51:970-5. doi:10.1161/HYPERTENSIONAHA.107. 107607

185. Knudsen UB, Kronborg CS, von Dadelszen P, Kupfer K, Lee SW, Vittinghus E, et al. A single rapid point-of-care placental growth factor determination as an aid in the diagnosis of preeclampsia. Pregnancy Hypertens (2012) 2(1):8-15. doi:10.1016/j.preghy.2011.08.117

186. Gullai N, Stenczer B, Molvarec A, Fugedi G, Veresh Z, Nagy B, et al. Evaluation of a rapid and simple placental growth factor test in hypertensive disorders of pregnancy. Hypertens Res (2013) 36:457-62. doi:10.1038/hr.2012.206

Conflict of Interest Statement: Hamutal Meiri and Sveinbjorn Gizurarson hold a patent for the use of the PP13 supplement to treat preeclampsia. All other co-authors have no conflict of interest.

Received: 23 May 2014; accepted: 08 July 2014; published online: 20 August 2014. Citation: Than NG, Balogh A, Romero R, Kárpáti É, Erez O, Szilágyi A, Kovalszky I, Sammar M, Gizurarson S, Matkó J, Závodszky P, Papp Z and Meiri H (2014) Placental Protein 13 (PP13) - a placental immunoregulatory galectin protecting pregnancy. Front. Immunol. 5:348. doi: 10.3389/fimmu.2014.00348

This article was submitted to Inflammation, a section of the journal Frontiers in Immunology.

Copyright (C) 2014 Than, Balogh, Romero, Kárpáti, Erez, Szilágyi, Kovalszky, Sammar, Gizurarson, Matkó, Závodszky, Papp and Meiri. This is an open-access article distributed under the terms of the Creative Commons Attribution License (CC BY). The use, distribution or reproduction in other forums is permitted, provided the original author(s) or licensor are credited and that the original publication in this journal is cited, in accordance with accepted academic practice. No use, distribution or reproduction is permitted which does not comply with these terms. 